\title{
PERCEPTIONS OF PROCEDURAL JUSTICE AND POLICE LEGITIMACY: A LIFE HISTORY PERSPECTIVE
}

\author{
By \\ Jody Dorgan
}

A thesis submitted to Victoria University of Wellington in fulfilment of the requirements for the degree of Master of Arts in Criminology

School of Social and Cultural Studies

Victoria University of Wellington

2016 
Perceptions of procedural justice and police legitimacy: A life history perspective

\begin{abstract}
Prior research on attitudes towards the police has largely focused on the relationship between demographic factors and perceptions of the police. These studies have produced inconclusive results, and there is no general consensus why and how demographic factors account for individual differences in attitudes towards the police. Life history theory, a "middle-level" evolutionary theory, is one that has largely been neglected in mainstream criminology, but has been used in the current research to explain individual differences in attitudes towards the police. Two studies, both using an online survey, were conducted to explore the extent to which life history strategy explained individual attitudes towards procedural justice, police legitimacy and police socialization after controlling for demographic factors, previous police interaction and prior arrest. Study one, a university sample of 305 participants and study two, a general population sample of 75 Wellington residents both found support for the application of life history theory being used to explain individual differences in attitudes towards the police. Overall, the current research showed that those with a slower life history strategy were more likely hold more positive perceptions of police legitimacy, procedural justice and police socialization regardless of demographic factors, previous police interaction, and prior arrest.
\end{abstract}


Perceptions of procedural justice and police legitimacy: A life history perspective

\section{Acknowledgments}

To my supervisor, Dr Russil Durrant, thank you for all your hours of guidance and support over the past year. Thank you for your patience with all my SPSS queries.

Connor, thanks for your encouragement and funnies, for always knowing what to say, for never indulging in a pity party with me, but for always indulging in my caffeine addiction with me.

To my friends, for keeping me sane outside of study. Especially to Imogen and Nicola for listening to my never-ending supply of thesis-related questions.

Finally, I would like to thank my family. Thank you for your constant support throughout my years of study and for making it possible for me to reach this point. I would not have been able to achieve this without you. To my Mum, for constantly believing in me, even when I may have doubted myself. And thanks for giving me a good push to carry on when I needed it! 
Perceptions of Procedural Justice and Police Legitimacy: A Life History Perspective

\section{Table of Contents}

$\begin{array}{lll}\text { Abstract } & \text { ii }\end{array}$

$\begin{array}{ll}\text { Acknowledgments } & \text { iii }\end{array}$

$\begin{array}{ll}\text { Introduction } & 1\end{array}$

Aims of the Research

Rationale for the Present Research 4

$\begin{array}{ll}\text { Literature Review } & 5\end{array}$

Police Legitimacy and Procedural Justice 5

$\begin{array}{ll}\text { Attitudes Towards the Police } & 15\end{array}$

Evolutionary Approaches in Criminology 25

Life History Theory 26

Life History Theory and Attitudes Towards the Police 36

Previous Research Examining the Link Between Life History Theory and 46 Attitudes Towards the Police

$\begin{array}{ll}\text { The Current Study } & 48\end{array}$

Methods $\quad 51$

General Overview $\quad 51$

Ethics $\quad 51$

$\begin{array}{ll}\text { Study } 1 & 53\end{array}$

$\begin{array}{ll}\text { Participants and Design } & 53\end{array}$

$\begin{array}{ll}\text { Procedure } & 53\end{array}$

$\begin{array}{lr}\text { Materials } & 55\end{array}$

$\begin{array}{lr}\text { Analysis } & 59\end{array}$

$\begin{array}{ll}\text { Results } & 60\end{array}$ 
Perceptions of Procedural Justice and Police Legitimacy: A Life History Perspective

$\begin{array}{lr}\text { Study } 2 & 67\end{array}$

$\begin{array}{ll}\text { Participants and Design } & 67\end{array}$

$\begin{array}{ll}\text { Procedure } & 67\end{array}$

$\begin{array}{ll}\text { Materials } & 70\end{array}$

$\begin{array}{ll}\text { Analysis } & 72\end{array}$

$\begin{array}{ll}\text { Results } & 74\end{array}$

$\begin{array}{ll}\text { General Discussion } & 81\end{array}$

$\begin{array}{ll}\text { Demographic Factors } & 82\end{array}$

Attitudes Towards Police Legitimacy, Procedural Justice and Police Socialization $\quad 85$

Prior Police Interaction and Prior Arrest 86

$\begin{array}{lr}\text { Community Dangerousness } & 87\end{array}$

Life History Traits and Attitudes Towards the Police 88

The Environment and Attitudes Towards the Police 90

$\begin{array}{ll}\text { Limitations } & 91\end{array}$

$\begin{array}{ll}\text { Implications } & 92\end{array}$

$\begin{array}{ll}\text { Future Research } & 95\end{array}$

$\begin{array}{lr}\text { Conclusion } & 96\end{array}$

$\begin{array}{ll}\text { Appendices } & 99\end{array}$

$\begin{array}{ll}\text { References } & 115\end{array}$ 
Perceptions of Procedural Justice and Police Legitimacy: A Life History Perspective

\section{List of Tables and Figures}

\section{Tables}

1. Comparison of faster and slower life history strategies 30

2. Descriptive statistics for all variables: Study $1 \quad 61$

3. Zero-order correlations among the study variables: Study 1

4. Summary of linear regression analysis for variables predicting 65 procedural justice: Study 1

5. Summary of linear regression analysis for variables predicting 65 police legitimacy: Study 1

6. Summary of linear regression analysis for variables predicting police socialization: Study 1

7. Descriptive statistics for all variables: Study $2 \quad 75$

8. Zero-order correlations among the study variables: Study $2 \quad 76$

9. Summary of linear regression analysis for variables 78 predicting procedural justice: Study 2

10. Summary of linear regression analysis for variables $\quad 79$ predicting police legitimacy: Study 2

11. Summary of linear regression analysis for variables 79 predicting police socialization: Study 2

\section{Figures}

1. Distal and proximate features leading to individual differences in perceptions of procedural justice, police legitimacy and police socialization. 
Perceptions of Procedural Justice and Police Legitimacy: A Life History Perspective

\section{Introduction}

The police as an organization rely on the support of members of the community more than any other public service organization in order to effectively maintain social order and to fight crime (Johnson, 1993; Miller, Davis, Henderson, Markovic \& Ortiz, 2004; Schafer, Huebner \& Bynum 2003; Sunshine \& Tyler, 2003a). The police rely on the public to willingly report crimes, suspicious behavior or activity, and crucial information relating to a crime or a criminal to maximize the effectiveness and efficiency of their investigations. In order for this to happen, a positive relationship between the police and the public is necessary (Hinds \& Murphy, 2007). Thus investigating and understanding public opinion of the police is a crucial area of study. There has been an abundance of literature (e.g., Brown \& Benedict, 2002; Chow, 2012; Correia, Reisig \& Lovrich, 1996; Hinds, 2007; Miller et al., 2004; Nettle, 2010; Reisig \& Parks, 2000; Schafer et al., 2003; Schuck, Rosenbaum \& Hawkins, 2008; Sunshine \& Tyler, 2003a; Sunshine \& Tyler, 2003b; Weitzer, 1999; Weitzer \& Tuch, 2004) analyzing the relationship between demographic factors (such as age, gender, socio-economic status, and ethnicity) and attitudes towards the police. However, these studies have produced inconclusive results and individual differences in attitudes towards the police are yet to be fully understood. It is therefore necessary to expand beyond demographic factors, and explore how other factors may influence individual attitudes towards the police.

Researchers have argued that studies examining attitudes towards the police have often produced inconsistent results due to a lack of theoretical guidance (Kruger, Nedlec, Reischl \& Zimmerman, 2015). An area yet to be analyzed in New Zealand is the application of a life history framework to public perceptions of the police. This is 
Perceptions of Procedural Justice and Police Legitimacy: A Life History Perspective

a new area of research in general within the field of criminology, and only one other study (Kruger et al., 2015) has previously explored the relationship between life history theory and attitudes towards the police. Life history theory is a "middle-level" evolutionary theory (Kruger, Munsell \& French-Turner, 2011), and such theories have been widely neglected in criminology (Boutwell et al., 2015; Durrant \& Ward, 2015; Wiebe, 2012). Life history theory examines how individuals adapt their behavioural strategies to best suit the conditions of the environment that they reside in during critical periods in development (Durrant \& Ward, 2015). Individual life history strategies can be placed upon a continuum between slow and fast life histories (Del Giudice, Gangestad \& Kaplan, 2015; Durrant \& Ward, 2015), and the current study argues that different characteristics of each strategy can be used to explain individual differences in perceptions of the police.

More specifically, the current study will examine how different life history strategies can explain individual attitudes towards police legitimacy and procedural justice in New Zealand. Police legitimacy and procedural justice are two concepts that have been shown to be of critical importance when understanding public opinion of the police (Sunshine and Tyler, 2003a; Tyler, 2004; Tyler, 2006). Prior research has demonstrated that when people view the police as a legitimate and procedurally just organization, they are more likely to hold a positive perception of the police (Chow, 2012; Hinds, 2007; Hinds \& Murphy, 2007; Sunshine \& Tyler, 2003a; Tyler, 2004; Tyler \& Fagan, 2008a). Prior studies have shown that when people perceive the police as legitimate, fair and procedurally just, they are more likely to cooperate with the police, comply with the police, contact the police, and support and empower the police (Sunshine and Tyler, 2003a; Tyler, 2004; Tyler, Fagan \& Geller, 2014). Previous research in New Zealand has shown that generally the majority of people are 
Perceptions of Procedural Justice and Police Legitimacy: A Life History Perspective

satisfied with the police (Paulin, Searle \& Knaggs, 2003). There are however, a percentage of residents who express dissatisfaction with the police, in particular younger residents (Paulin, Searle \& Knaggs, 2003) and ethnic minority groups (Ho, Cooper \& Rauschmayr, 2006; Paulin, Searle \& Knaggs, 2003; Te Whaiti \& Roguski, 1998). Thus there is room to improve the police-public relationship in New Zealand.

\begin{abstract}
Aims of the Research
The main aim of the current research is to examine whether a slower life history strategy will predict more favourable attitudes towards the police (procedural justice), and greater willingness to collaborate and interact with the police (police legitimacy) within a New Zealand context. As such, the current study aims to extend on the findings of Kruger et al. (2015) in a New Zealand context. The study will be conducted through two online studies, one with a student sample and one with a general population sample from the Wellington region. The research questions for the current study are:
\end{abstract}

1) To what extent does life history strategy explain perceptions of police legitimacy?

2) To what extent does life history strategy explain perceptions of procedural justice?

3) To what extent does life history theory have an influence on measures of police socialization?

4) Do females display a slower life history strategy than males?

5) Do younger individuals display a faster life history strategy than older individuals?

6) Do ethnic minority groups display a faster life history strategy 
Perceptions of Procedural Justice and Police Legitimacy: A Life History Perspective

compared to non-minority ethnic groups?

7) Do those of a lower socio-economic status display a faster life history strategy than those of a higher socio-economic status?

\section{Rationale for the Present Research}

This research will explore how a life history framework, which has been largely neglected in criminology (although see Boutwell et al., 2015; Dunkel, Mathes \& Beaver, 2013; Richardson, 2016; Wiebe, 2012) can be useful when applied to understanding outcomes relevant to criminal justice. The application of a life history framework to understanding attitudes towards the police has not previously been employed in a New Zealand context, and is a new area of research to criminology in general. The existing body of research on attitudes towards the police has often produced conflicting results and has been described as 'fuzzy' (Chow, 2012). More research is needed in order to clarify the current findings surrounding the relationship between attitudes towards the police and individual factors such as ethnicity, gender, age, socio-economic status, and neighbourhood characteristics.

In a previous study Kruger et al. (2015) found that life history speed was associated with demographic factors including gender, age, and level of educational attainment. Although there was an association between life history and demographic factors, they did not provide an explanation for the relationship between life history and attitudes towards the police. Kruger et al. (2015) then controlled for demographic factors and found that a slower life history strategy was associated with increased perceptions of police legitimacy and procedural justice. Research that will enhance the understanding of individual differences in attitudes towards the police is a valuable area of research that has important implications for the police, the public, society as a whole, and for policy markers. 
Perceptions of Procedural Justice and Police Legitimacy: A Life History Perspective

\section{Literature Review}

\section{Police Legitimacy and Procedural Justice}

In order for the police to function effectively, crime to be managed, and for laws to be upheld by society, the police need the support of the public (Miller, Davis, Henderson, Markovic \& Ortiz, 2004; Schafer et al., 2003; Sunshine \& Tyler, 2003a). Greene (2000, pg. 333) describes the role of policing in society as:

An information gathering and processing function that seeks to identify a wide variety of problems and/or conditions in community settings that give rise to crime, disorder, fear, and victimization and then to respond to those problems and/or conditions. As an information processing system, the police have come to rely on the public as the primary source of information and mobilization of police responses.

In recent years, the focus of policing has shifted from a traditional model of policing

to a community-based model of policing, which places more emphasis on community level problems, crime prevention, victim assistance, and building a relationship between the police force and members of the public (Greene, 2000). The police have focused on improving police/public relations, so the two can work collaboratively to prevent and target crime (Greene, 2000). A large body of research has examined public compliance with the police - the public must obey the police and their laws if social order is to be upheld and maintained (Tyler, 2004). The capability of the police to secure public compliance with them as an organization, and more broadly with the general law, has been seen as one of the main measures of their viability as authority figures (Tyler, 2004). This has typically been measured by the extent to which the police successfully exercise their authority (Tyler, 2004). The police need the public to obey them during any encounters between the police and the public, but also during 
Perceptions of Procedural Justice and Police Legitimacy: A Life History Perspective

people's everyday behaviour so that the law is upheld (Tyler, 2004). Gaining obedience from citizens is only one aspect of the support that the police need from the public; they also need co-operation from the public if they want to successfully lower and manage crime and disorder in the community (Mazerolle, Antrobus, Bennett \& Tyler, 2012; Tyler \& Fagan, 2008b).

Given that co-operation with the police is such an important aspect of maintaining social control, we need to understand how co-operation is generated and maintained (Gau, 2014; Tyler, 2004). The vast majority of research has examined instrumental models of policing (Sunshine \& Tyler, 2003; Tyler, 2004). An instrumental perspective argues (Sunshine \& Tyler, 2003; Tyler, 2004; Tyler \& Fagan, 2008a) that co-operation and compliance with the police stems from:

1) The threat of punishment that the police have in place if someone breaks the law. It states that people are motivated to comply with the law because they do not want to be punished for breaking the law, or because there are incentives for complying with the law - such as avoiding punishment.

2) The effectiveness of police in controlling criminal activity and disorder.

3) An equal distribution of services across all people and communities (distributive fairness).

In other words, an instrumental model of policing is based around the argument of an individual's personal self-interest (Tyler \& Fagan, 2008). This model argues that people are motivated to comply with the police in order to avoid punishment. Research, however, has shown that instrumental models are insufficient in explaining public co-operation with police (MacCoun, 1993; Tyler, 2004; Tyler, 2008). Threats of punishment, police effectiveness in controlling crime, and distributive fairness 
Perceptions of Procedural Justice and Police Legitimacy: A Life History Perspective

have been found to be only loosely linked to public perception of the police (MacCoun, 1993; Tyler, 2004; Tyler, 2008).

An approach that has shown much more empirical evidence (Hinds, 2007; Hinds \& Murphy, 2007; Sunshine \& Tyler, 2003a; Tyler, 2004; Tyler, 2008; Tyler, Fagan \& Geller, 2014) in explaining co-operation with the police is a legitimacy approach, which incorporates procedural justice. This approach is largely based upon Tyler's process-based model of policing (Tyler, 2004), a social-psychological framework that examines the workings of police-public relations. Central to this model are the concepts of legitimacy and procedural justice.

\section{Legitimacy}

A procedural justice approach to understanding individual attitudes towards police is based upon perceptions of police legitimacy. Public perceptions of police legitimacy have been demonstrated to be a crucial element of the relationship between the public and the police (Chow, 2012; Hinds, 2007; Hinds \& Murphy, 2007; Sunshine \& Tyler, 2003a; Tyler, 2004; Tyler, 2008). Sunshine and Tyler (2003a) define legitimacy as, "A property of an authority or institution that leads people to feel that the authority or institution is entitled to be deferred to or to be obeyed" (p. 514). People feel obligated to obey the laws set by an authority not only because of the authorities ability to use coercion or reward, but also because of the properties of the authority that make people feel that it is entitled to be obeyed (Gau, 2014; Sunshine and Tyler, 2003a). In other words, people are more likely to co-operate with the police if they feel they have an obligation toward the police to do so.

Legitimacy entails an acceptance of the police and their rules and a willingness to co-operate with them because they are seen as an organization that are trusted to enforce laws that are serving the best interests of all people in society (Gau, 
Perceptions of Procedural Justice and Police Legitimacy: A Life History Perspective

2014). Tyler (2004) argues that when people feel that an authority, such as the police, are legitimate then they will authorize them to govern their behaviour. This approach therefore reflects a social value that is separate from self-interest, which the police must appeal to in order to gain co-operation from the public (Hinds \& Murphy, 2007; Tyler, 2008).

Legitimacy towards the police can be measured by the perceived obligation people feel to obey them, the level of trust and confidence people have in the police, general feelings towards the police, and the extent to which people identify with the police (Tyler, 2008). The police rely in part on the public to help them be effective in their roles as maintainers of social order. The police need the public to co-operate with them by not only obeying the law, but also by helping them to control crime and lower it within our communities (Miller et al., 2004; Tyler, 2008). This co-operation includes behaviours such as reporting crimes, helping to identify criminals and assisting police with their investigations, participating in neighbourhood watch groups, and expressing a general positive attitude towards the police as authority figures (Tyler, 2004; Tyler, 2008). Those who believe the police are legitimate are more likely to contact the police voluntarily, initiate contact with the police or voluntarily help the police (Skogan, 2005). This includes actions such as reporting a crime, reporting suspicious activity, or acting as a witness (Skogan, 2005). This behaviour from the public is largely voluntary in nature. The police do not generally reward these behaviours, or use force to ensure they occur; they simply rely on the public to voluntarily cooperate with them and help them maintain social order (Tyler, 2004).

Previous research has shown that it is challenging for the police to gain voluntary co-operation from citizens (Gau, 2014). If the police can generate feelings 
Perceptions of Procedural Justice and Police Legitimacy: A Life History Perspective

of legitimacy from the public then there is a higher likelihood of laws being obeyed compared to if they rely on instrumental measures to secure compliance (Tyler, 2004). Research has shown that when an authority possesses legitimacy, the public is more likely to accept their decision-making processes, follow the rules that they set and feel more satisfied with their decisions (Tyler, 1990; Tyler, 2006; Tyler \& Huo; 2002). Tyler and Huo (2002) conducted a study on attitudes towards the police in Los Angeles and Oakland in the United States. The researchers found the two factors that influenced resident's acceptance of police decisions were the extent to which decisions were considered as fair and favourable and, most importantly, the extent to which the police were generally considered as legitimate.

Tyler and Sunshine (2003a) and Tyler, Fagan \& Geller (2014) found that legitimacy had an extensive impact on empowerment of the police, cooperation with the police, and compliance with the police. As mentioned, perceived legitimacy does not rely on incentives or punishments from the police; it is motivated by the personal values of the public (Tyler, 2008). This difference in motivation is a key difference between an instrumental and a legitimacy/procedural justice approach. It has been shown that in order for people to feel obligated to an authority they must possess a social orientation toward the authority such as a moral, normative or ethical feeling of responsibility to follow the rules set (Hinds \& Murphy, 2007; Sunshine \& Tyler, 2003b).

In this sense, a legitimacy approach is therefore based on self-regulatory behaviour - people will regulate their behaviour on their own accord because they feel internally motivated to do so. As Hoffman (1977, p.85) states, "Control by others is replaced by self-control, as social norms and values are internalized and become part of the individual's own desires concerning how to behave." This means that the 
Perceptions of Procedural Justice and Police Legitimacy: A Life History Perspective

public will be more inclined to obey the police in all situations where as an instrumental perspective would theoretically provide society with more opportunity to only comply with the police in situations where there is a strong chance of being punished. This is an important concept for the police because they cannot be present everywhere and all of the time. It is not viable for the police to be constantly monitoring behaviour in society - they do not have the time, or the resources. In addition, there is the ethical question about constant surveillance of society (Tyler, 2006). The police therefore benefit from the public actively wanting to and feeling that they should co-operate and comply with the police as they can spend less time and resources on constant surveillance. The police can also spend less time and resources on threats of punishment and promises of reward if they can gain voluntary co-operation from the public.

In order for the police to enhance public perceptions of legitimacy, research has shown that acting in a procedurally just manner leads to more positive perceptions of legitimacy (Gau, 2014; Mazerolle et al., 2012; Tyler, 2004). When the public hold more positive perceptions of police legitimacy, they are more likely to initiate contact with the police and to cooperate with the police (Kruger et al., 2015) - two key behaviours of the legitimacy model. This then leads to a greater likelihood of lawabiding behaviour (Sunshine \& Tyler, 2003a), and a more supportive attitude toward new police ventures, such as community policing initiatives (Posisk, Rocque \& McDecitt, 2013). As mentioned, the majority of the research in this area originates from Tyler's process-based model of policing, which focuses on the concepts of police legitimacy and procedural justice (Tyler, 2004). The model argues that the police can increase public perception of police legitimacy by acting in a fair manner, and by explaining the rationale for decisions that they make. In other words, the 
Perceptions of Procedural Justice and Police Legitimacy: A Life History Perspective

police can increase public perception of police legitimacy by acting in a procedurally just manner. When the police consider these aspects in their social interactions with the public, the public are more likely to have a positive attitude toward the police (procedural justice), and be more willing to interact and cooperate with the police (police legitimacy).

\section{Procedural Justice}

The current literature demonstrates that the most crucial factor that influences the public's perceptions of police legitimacy is procedural justice (Hinds \& Murphy, 2007). Thibaut and Walker (1975) were the first researchers to highlight the individual factors that influence people's satisfaction with an authority figure or institution. These factors include both the procedures used by the authority to make its decision, and the outcomes of the decision. Thibaut and Walker (1975) subsequently devised the term 'procedural justice' to refer to people's perceptions and opinions of the treatment they receive during the decision making process. Importantly, people's satisfaction with the decision making process and the treatment received during this time was not exclusively dependent on the outcome of the decision (for example, a conviction of guilt or innocence). Since this early study conducted by Thibaut and Walker (1975), further research has continued to demonstrate that people's satisfaction with an authority is linked to their perceptions of the procedural justice aspects of their encounter with the aforementioned authority figure or institution (Hinds \& Murphy, 2007).

According to a procedural justice approach, people's assumptions about the legitimacy of the police are based upon the level of appropriateness that people feel the police demonstrate in their work and their actions (Posick, Rocque \& McDevitt, 2013; Sunshine and Tyler, 2003a). If the public feel that the police are demonstrating 
Perceptions of Procedural Justice and Police Legitimacy: A Life History Perspective

fairness in their procedures and in their authority, and feel the police have explained the rationale behind their decisions, then they are more likely to cooperate with them and view them as legitimate. If the public believe that the police are exercising unfairness in their authority then this will lead to feelings of illegitimacy, along with defiance and noncooperation (Sunshine and Tyler, 2003a; Tyler, 2004). Tyler (2004) stipulates the following key aspects of procedural justice for the public during an encounter with the police:

1) Active involvement in discussions before the police make their decisions, such as being given the chance to explain their views and behaviour before the police decide on what course of action to take.

2) The police have made decisions that are fair, neutral, and impartial.

3) The police have treated the individual with respect, and dignity.

Examples of procedural injustice include actions from the police such as unwarranted stops, verbal and physical abuse, and feelings of prejudicial behaviour (Weitzer \& Tuch, 2004). When citizens encounter these behaviours from the police they are inclined to view them as invasive, disrespectful, and unfair (Weitzer \& Tuch, 2004). This will subsequently lead to citizens holding an overall lower opinion of the police.

As mentioned, a procedural justice approach focuses on the perception of fairness during an interaction with a member of the public, regardless of the actual outcome of the situation. Skogan (2005) and Tyler (2004) demonstrated that people were more likely to accept the actions of the police during an encounter with them if they believed the police had acted fairly and appropriately, even if the outcome was not the one that the person desired. For example, a study conducted by Sunshine and Tyler (2003a) in New York showed that people's perceptions and evaluations about 
Perceptions of Procedural Justice and Police Legitimacy: A Life History Perspective

the legitimacy of the New York police were predominately based on perceptions of procedural justice, and to a lesser extent on the outcomes of interactions between the police and the public.

This is critical for the police, as they cannot guarantee that the outcome of an interaction with the public will be an outcome that the public had desired. Therefore, knowing that the police have support, cooperation, and respect from the public in spite of any decisions that they may make should be a crucial element of focus for the police. Research has shown that after controlling for other factors people who feel they receive respectful treatment from the police are twice as likely to comply with their instructions, while on the other hand, those who feel they have received disrespectful treatment are twice as likely to rebel (Skogan, 2005). It has also been demonstrated that when citizens feel the police patiently discuss a situation with them, they again are twice as likely to comply with the requests of the police (Skogan, 2005).

Studies have also shown that the perceptions of how individuals are treated during an encounter with the police will affect later beliefs about the police and behaviours towards the police (Hinds \& Murphy, 2007; Mazerolle et al., 2013; Sunshine \& Tyler, 2003; Tyler, 2006). This is a central aspect demonstrating the importance of public perceptions of the actions of the police, as their opinions will affect whether they will co-operate and comply with the police in the future or not. An individual's belief about how procedurally just the interaction was will affect not only the interpretation of any future interactions with the police, but also affect peoples general opinions of the police. A study by Tyler (1990) demonstrated that police use of procedural justice is the most critical factor in shaping people's overall general judgments about the police. The study in Chicago showed that residents' 
Perceptions of Procedural Justice and Police Legitimacy: A Life History Perspective

overall satisfaction with the police was based on whether or not people perceived the police had treated them with dignity and respect, and whether or not the police had provided them with an opportunity to explain their behaviour. In other words, whether or not residents believed that they had been treated in a procedurally just manner.

Tyler (2004) has argued that perceptions of police legitimacy and fairness are based on an individual's own feelings of responsibility and obligation towards the police and the law. Therefore the public need to feel a social commitment to upholding the law, and believe that the police represent the values of their society (Sunshine and Tyler, 2003b). The public need to feel that the police are actively working with their community in the residents' best interests. This is much more likely to happen if the public feel that police actions are representative of the community's values, norms, and preferences (Tyler 2004; Tyler, 2008). In other words, the police are more likely to activate internal voluntary feelings of cooperation and compliance if the public feel they can relate to the police, their decisions and their actions.

\section{Summary}

In summary, viewing the police as legitimate, fair, and procedurally just has been shown to increase the public's level of compliance, cooperation, and contact with the police, and increase the public's support for empowerment of the police (Sunshine and Tyler, 2003a; Tyler, 2004). From a legitimacy perspective, public cooperation and compliance with the police is largely voluntary in nature and requires the public to feel that the police are deserving of their co-operation, and that the police exercise their authority fairly. Voluntary co-operation and compliance with the police is much more likely to occur if the public feel that the police are representative of their norms and values, and are working to achieve such norms and values in a 
Perceptions of Procedural Justice and Police Legitimacy: A Life History Perspective

legitimate and procedurally just way. Procedural justice has been shown to be the most crucial factor in determining individual attitudes towards police legitimacy. Both legitimacy and procedural justice are therefore critical aspects of the police-public relationship. Therefore understanding what factors influence individual differences in perceptions of police legitimacy and procedural justice is a highly valuable area of research.

\section{Attitudes towards the police}

Why do some people readily co-operate with the police more than others? Why do some members of society view the police as a legitimate organization while others see them as an illegitimate group not to be trusted? While research has demonstrated that most people generally support the police and are mostly satisfied with the way they perform their duties, it has also shown that not all members of society have equally positive opinions (Miller et al., 2004). Prior research has shown a relationship between attitudes towards the police and individual factors such as ethnicity, gender, age, socio-economic status, and neighbourhood characteristics, but the reasons behind these findings have been described as 'fuzzy' (Chow, 2012). Research has demonstrated that these individual factors have an effect on how people view the police, and yet the causes of the relationship between these factors and individual attitudes towards the police are still not fully understood (Miller et al., 2004; Weitzer \& Tuch, 2004).

\section{Ethnicity}

Ethnicity is one of the most significant predictors of attitudes towards the police. Studies have repeatedly shown that members minority ethnic groups tend to hold less favourable attitudes towards the police and have lower trust and confidence 
Perceptions of Procedural Justice and Police Legitimacy: A Life History Perspective

in the police compared to members of non-minority ethnic groups (Chow, 2012; Correia, Reisig \& Lovrich, 1996; Schafer, Heubner \& Bynum, 2003; Schuck et al., 2008; Sunshine \& Tyler, 2003a; Weitzer, 1999; Weitzer \& Tuch, 2004). Research in America has shown that ethnic minorities are more likely to have a higher number of negative contacts with the police than the majority ethnic group are (Correia, Reisig \& Lovrich, 1996). Research has found that African Americans are more likely to leave an encounter with police feeling angry, upset or as if they have not been treated in a procedurally just way (Weitzer \& Tuch, 2004). This means African Americans are more likely to have a negative attitude toward the police (Schafer et al., 2003).

Weitzer and Tuch (2004) found that African Americans were more likely to believe that police were very frequently involved in acts of procedural injustice including unwarranted stops of citizens, the use of excessive force and abuse, and corruption. Members of non-minority ethnic groups on the other hand, were found to believe that police were never or only very occasionally involved in these activities, and were inclined to deny the existence of police misconduct. Weitzer and Tuch (2004) also found that African Americans and Hispanics were more likely than members of non-minority ethnic groups to actually have encountered personal or vicarious experiences of police misconduct, and that they were more likely to have experienced repeated incidents of police misconduct. These experiences of procedural injustice would consequently lead to a negative view of police legitimacy, and lead to a more negative attitude toward the police.

Citizens who have been subject to more involuntary contact with the police, such as frequent stops by the police, are more likely to hold an overall negative attitude of the police (Schafer et al., 2003). Given that members minority groups are more subject to involuntary contact with the police in comparison to their non- 
Perceptions of Procedural Justice and Police Legitimacy: A Life History Perspective

minority counterparts (Weitzer, 1999; Weitzer \& Tuch, 2004), this is likely to increase the likelihood that they will have negative attitudes toward the police. Research has also shown that African Americans are less likely to cooperate with the police, including reluctance to give witness statements and provide evidence in court (Viki, Eller \& Abrams, 2006).

In New Zealand, research has consistently demonstrated that Māori are overrepresented within the criminal justice system (Bradley \& Walters, 2011) but there is a lack of research analysing specific attitudes of Māori towards the police. Quince (2007) has shown that the relationship between Māori and New Zealand police has historically been strained and continues to be problematic today. One large-scale study conducted by Te Whaiti \& Roguski (1998) found that all Māori that they spoke to (roughly 80 Māori participants) felt a strong attitude of distrust towards the police. The participants also said they would be reluctant to contact the police to offer assistance or even to contact them if a crime had been committed against them. Overall the participants had a lack of faith in the police as an organization and felt that the police abuse their power, and act in a racist manner towards Māori.

Another study by Ho, Cooper and Rauschmayr (2006), which was commissioned by the New Zealand police, explored perceptions of police among Asian and African individuals living in New Zealand. Their results found that only a small number of people from these ethnic minority groups had made contact with the police for non-crime related reasons, and the same groups felt reluctant to contact the police for crime-related matters as well. A number of participants had negative perceptions of the police, stating that the police did not act in a fair manner and acted in a prejudiced fashion towards them. Participants described the police as, 
Perceptions of Procedural Justice and Police Legitimacy: A Life History Perspective

"unapproachable", "powerful", and "intimidating" and said that the police "don't protect us" (p. 15). Participants also said that when they had previously been involved in an incident with the police, they felt the police had not listened to their side of the story, which has been demonstrated to be a crucial aspect of perceptions of procedural justice.

A small number of participants in the study had, however, made contact with the police for non-crime related matters, and a sample of the participants also had positive perceptions of the police. The participants who had a positive image of the police described them as "helpful", "approachable", and "kind" (p.15). The fact that there is mixed perceptions of the police from ethnic minority groups demonstrates that ethnicity alone cannot account for the individual attitudes towards the police held by the public. The 2013 census in New Zealand (Statistics New Zealand, 2015) showed that $15 \%$ of the population identify as Māori, $12 \%$ identify as Asian, and $7 \%$ identify as Pacific. Given that $34 \%$ of the population in New Zealand identify as Māori, Asian or Pacific more research is needed to help understand the reasoning behind their individual attitudes towards the police. This is particularly important in a settler society like New Zealand, where the relationship between the police and Māori in particular has often been tense (Gravitas, 2010; Maxwell \& Smith, 1998; Te Whaiti \& Roguski, 1998).

Research by Skogan (2005) found that feelings of legitimacy and procedural justice had more of an influence on attitudes towards police than ethnicity. This study found that ethnicity was only loosely linked with attitudes towards the police, and argued that perceptions of fair treatment had more of an impact on attitudes towards the police regardless of an individual's ethnicity. Weitzer (1999) conducted a study in 
Perceptions of Procedural Justice and Police Legitimacy: A Life History Perspective

America and the results showed that lower class African Americans have a more negative perception of the police and police behaviour than middle class African Americans do. These findings suggest that while ethnicity is a predicator of attitudes towards police, ethnicity alone cannot solely account for individual attitudes towards the police given there are differences not only between ethnicity groups but also within ethnicity groups.

\section{Age}

There are also mixed findings as to what extent age predicts attitudes towards the police. Some studies have found no relationship between age and attitudes towards the police (Correia, Reisig \& Lovrich, 1996; Scaglion \& Condon, 1980). A large number of studies have, however, established that younger people hold more negative opinions of the police than older people do (Brown \& Benedict, 2002; Chow, 2012; Hinds, 2007; Miller et al., 2004; Reisig \& Parks, 2000; Schafer et al., 2003; Weitzer, 1999). Brown and Benedict (2002) who reviewed 100 papers on attitudes towards police assert that age is the only reliable predictor of attitudes towards the police. Younger citizens are subject to an increased number of involuntary stops by the police, and it is more likely that these will be viewed as unjust because they tend to interpret these stops as if they are being 'picked on' or told to 'move on' (Hinds, 2007). Younger people believe that the police feel they are 'up to no good' even if they are doing nothing wrong, and this leads to a decreased perception of police legitimacy (Devaney, Pehrson, Bryan \& Blaylock, 2014). As mentioned, citizens who have more involuntary contact with the police, such as frequent stops by the police, are more likely to have a negative attitude towards the police (Schafer et al., 2003).

Younger people also commit a disproportionate amount of crime (Durrant \& Ward, 2015), and therefore come into more contact with the police than older people 
Perceptions of Procedural Justice and Police Legitimacy: A Life History Perspective

do. The more negative interactions that younger people have with the police then unavoidably, the more negative views of the police they are likely to develop (Hinds, 2007; Schafer et al., 2003). Since younger people tend to hold more negative views of the police in general, they are more likely to development feelings of resentment towards the police and consequentially show less respect towards the police during any interactions they may have with them (Hinds, 2007).

A study by Hurst and Frank (2000) looked at the attitudes of high school adolescents in America towards the police. The results from this study showed that less than four in ten of the students said they trusted the police or that they were satisfied with the police. Hinds (2007) found that the strongest positive predictor of young people's perceptions of police legitimacy was procedural justice, showing how important it is that police interactions are viewed as just and fair. Fagan and Taylor (2005) have demonstrated that when young people feel the police are illegitimate then they are less likely to comply with the law. Studies have found that older citizens feel more satisfied with the police and are more likely to believe that they are doing a better job (Hinds, 2007; O'Connor, 2008), thereby increasing the likelihood that they will view the police as a legitimate organization and increasing their compliance with the law.

\section{Gender}

Again, there is mixed evidence surrounding the relationship between gender and perceptions of the police. Reisig and Parks (2000) and Brown and Bendict (2002) found no gender differences when looking at attitudes towards the police, and found that gender did not significantly predict individual attitudes towards the police. Correia et al. (1996) discovered that females held more negative perceptions of the police than their male counterparts. Skogan (2005) conducted a study, which showed 
Perceptions of Procedural Justice and Police Legitimacy: A Life History Perspective

that while males were more likely to be stopped by police or come into contact with the police, gender did not significantly predict how citizens viewed the police during these encounters.

On the other hand, a large body of evidence has found that gender does influence perceptions of police. Studies have shown that females generally hold more positive perceptions of the police, and are more likely to show support for the police (Brandt \& Markus, 2000; O’Connor, 2008; Stewart, Morris \& Weir, 2014; Sunshine \& Tyler, 2003a). Sunshine and Tyler (2003a) found that females were more likely to comply with the police and with the law overall. Tyler and Fagan (2008) showed that females were more likely than males to initiate contact with the police. This has important implications for the police because if the public perceives them as legitimate then citizens are more likely to willingly initiate contact with them, which can include important behaviours such as reporting crime or assisting in investigations. A study conducted in Australia by Sargeant and Mazerolle (2012), which looked at gender differences in attitudes towards the police, found that females reported more positive perceptions of the police across a number of aspects of policing. Females held more positive perceptions of procedural justice, law legitimacy, police legitimacy, trust in the police, police effectiveness, and willingness to co-operate with the police.

\section{Socio-Economic Status}

Research has consistently shown that those who are of a low socio-economic status are likely to have more negative perceptions of the police (Brown \& Benedict, 2002; Chow, 2012; Nettle, 2010; Scaglion \& Condon, 1980; Schafer et al., 2003, Sunshine \& Tyler, 2003a; Sunshine \& Tyler, 2003b). Sunshine and Tyler (2003a) 
Perceptions of Procedural Justice and Police Legitimacy: A Life History Perspective

found that those citizens who earned a higher income were more likely to co-operate with the police. African American residents in America are more likely to be disproportionally situated in lower socio-economic status areas (Reisig \& Parks, 2000), and in New Zealand Māori are more likely to be disproportionately situated in such areas (Quince, 2007). A study which was conducted in 15 American cities in 1958, showed that neighbourhood class and race was more influential on perceptions of the police than individual class and race. Citizens who resided in low income, largely African American neighbourhoods were most dissatisfied with the police and citizens who resided in upper income, largely white neighbourhoods were most satisfied with police performance (Weitzer, 1999). Thus in this study, the socioeconomic status of the community removed the effect of race on perceptions of police. It is therefore important to consider how these factors may interplay with one another, and further highlights the 'fuzziness' of individual attitudes towards the police.

Weitzer (1999) showed that African American citizens in a middle class neighbourhood in America were less likely to perceive the police as abusive and as exploiting their power than African Americans in lower class neighbourhoods (Weitzer, 1999). Those in lower class communities, or ghetto areas in America, tend to have higher crime rates and are therefore faced with more surveillance from the police and come into more contact with the police (Weitzer, 1999). Given that citizens in these areas are exposed to more general police contact, this means they also experience more involuntary contact. As Schafer et al. (2003) explained, citizens who have more involuntary contact with the police are more likely to hold an overall negative attitude towards the police (Schafer et al., 2003).

Neighbourhood Characteristics 
Perceptions of Procedural Justice and Police Legitimacy: A Life History Perspective

Research has largely looked at how demographic factors such as race and age influence individual perceptions of the police, but the effect of macro-level conditions such as neighbourhood characteristics has often been unobserved (Weitzer \& Tuch, 2004). An increasing amount of research suggests that neighbourhood context plays an important role in determining attitudes towards the police. Research has demonstrated that those who live in a neighbourhood that they perceive as unsafe or lacking community culture are likely to have more negative perceptions of the police (Brown \& Benedict, 2002; Chow, 2012; Nettle, 2010; Schafer et al., 2003; Sunshine \& Tyler, 2003b). Schafer et al. (2003) found that even if individuals have not had any prior interactions with the police, they often base their opinion on vicarious contact from others in the neighbourhood and formulate their opinion based on what their neighbourhood culture is towards the police. In other words, people are likely to pick up the norms of their neighbourhood surrounding attitudes towards police.

The "quality of life" model argues that perceptions of neighbourhood conditions influence satisfaction with police (Reisig \& Parks, 2000). The conditions that influence satisfaction include the perceived level of crime, safety, social disorder and decay in the neighbourhood. If these conditions are perceived to be high in a neighbourhood, then citizens are more likely to hold negative views of the police and be less satisfied with the police. Studies have shown that as the crime rate in a neighbourhood increases, satisfaction with the police decreases (O'Connor, 2008; Reisig \& Parks, 2000; Schafer et al., 2003). In their study, however, Reisig and Parks (2000) argued that the "quality of life" model could not fully account for the individual attitudes towards the police that they found, even though the results were significant. This again suggests that we cannot adequately explain the reasons behind individual attitudes towards the police with the current research available. 
Perceptions of Procedural Justice and Police Legitimacy: A Life History Perspective

Citizens who perceive that others in their neighbourhood do not help to protect one another from crime tend to show less satisfaction with the police than those who perceive their neighbourhood as more socially cohesive (Reisig \& Parks, 2000; Schafer et al., 2003). Notably with younger people, the connection to their neighbourhood and to the wider society often has an influence on how they view the police and the extent to which they will co-operate with the police (Devaney et al., 2014). As Sunshine and Tyler (2003b) argued, in order to feel a moral obligation towards the police, the public need to believe that the police represent the values of their society. In order for this to happen, people need to feel a connection to the morals of their own neighbourhood before they can feel a connection to the wider morals of the police.

Sun and Triplett (2008) have argued that there is a link between neighbourhoods that have a low evaluation of police legitimacy and a high rating of social disorder. They argue that there is a link between perceptions of legitimacy and important police issues including high rates of crime, negative police and community relations, and low levels of co-operation with the police. Ethnic minorities are more likely to be disproportionately located in these neighbourhoods (Reisig and Parks, 2000), including Maori citizens in New Zealand (Quince, 2007). It is therefore important to consider a combination of factors when analysing why ethnic minorities tend to hold less favourable attitudes towards the police than non-minority ethnic groups do. The current study argues it is too simplistic to assert that someone's ethnicity alone will influence his or her individual attitude towards the police.

\section{Summary}

Prior research has shown that there is a relationship between attitudes towards the police and factors such as ethnicity, age, gender, socio-economic status, and 
Perceptions of Procedural Justice and Police Legitimacy: A Life History Perspective

neighborhood conditions. Many studies have highlighted the importance of these factors when considering individual attitudes towards the police, and yet the reasons these factors influence people's perceptions has yet to be adequately and fully explained. The majority of studies have focused on the relationship between perceptions of police and demographic factors such as ethnicity, age, and gender. The results of these studies have often been inconsistent and have regularly produced conflicting results. While it is clear that such factors contribute to individual attitudes towards the police, a different approach is needed in order to understand why these factors influence perceptions of the police and how these different perceptions arise.

\section{Evolutionary Approaches in Criminology}

Evolutionary approaches in criminology base their arguments on the fact that humans have evolved over time, and their behaviour and psychological processes have adapted according to the evolutionary process (Durrant \& Ward, 2011). Such theories state that the origins of the underpinnings of behaviour, including behaviour relating to criminal justice, have roots in how humans have evolved through natural selection to best survive and reproduce (Campbell, 2013). The application of evolutionary frameworks to the criminal justice area has largely been underrepresented in the social science area (Durrant \& Ward, 2015).

There has been debate surrounding whether or not such frameworks can be applied to our understanding of outcomes relevant to criminal justice (Campbell, 2013). There have been criticisms that evolutionary theory is too focused on biological factors and does not place enough emphasis on social and cultural factors (Campbell, 2013). Since evolutionary theory essentially argues that all behaviour has roots in biology and genes, some have argued that it too simplistic and reductionist to understand something as complex as criminal behaviour (Campbell, 2013). As 
Perceptions of Procedural Justice and Police Legitimacy: A Life History Perspective

Durrant and Ward (2015) note, others have also argued that evolutionary theories of human behaviour are untestable, unfalisifiable and ideologically unsound. The current research will, however, argue that a life history framework (a "middle-level" evolutionary theory (Durrant and Ellis, 2013) can be useful when applied to understanding outcomes relevant to criminal justice. The current research will aim to demonstrate how life history theory can help explain individual differences in perceptions towards police legitimacy and procedural justice.

Although evolutionary theories have typically been overlooked in criminology, Laub (2006) contends there is increasing awareness that outcomes relevant to criminal justice can be understood by analysing an individual's wider developmental setting (e.g. developmental criminology). Durrant and Ward (2015) argue that development plays a key role in evolutionary theory. The development of any species is based upon an interaction between the organism's genes and the features of the environment in which it resides (Durrant \& Ward, 2015). Each organism therefore has its own characteristic developmental path that is specific to its particular species, but because developmental pathways are a product of both genes and environment, there are also within-species differences in each organism's development. This demonstrates the malleability of genetic influence and highlights the critical role that the environment has on an organism's developmental pathway.

\section{Life History Theory}

Life history theory is a "middle-level" evolutionary theory that also incorporates ecological, biological, psychological, and socio-developmental perspectives (Kruger, Munsell \& French-Turner, 2011). Such disciplines have previously been considered isolated from one another, however the use of life history theory can integrate knowledge from across these disciplines into one arguably 
Perceptions of Procedural Justice and Police Legitimacy: A Life History Perspective

powerful framework. A species' life history is its evolved course of birth, growth, development, reproduction and aging across the lifespan (Kruger et al., 2011). Life history theory states that species must allocate resources to each of these aspects during their lifespan, and that they must make trade-offs when they are allocating resources to each of these aspects. Certain features of an organism's evolved developmental history (meaning how an organism's developmental processes evolved over time, including genetic factors), alongside the environment in which the organism resides, will determine the optimum allocation of their time, resources, energy and behavioural strategies towards growth, development, reproduction, and survival across the lifespan (Del Giudice at al., 2015; Durrant \& Ward, 2015; Kruger et al., 2011).

From an evolutionary perspective, the fitness of any organism describes their ability to pass on their genes to future generations, which is dependent upon their reproductive and survival success (Figueredo et al., 2014; Kruger et al., 2011). All organisms are posed with an important challenge of how to successfully allocate resources, time, and energy across the many different tasks crucial for survival and reproduction (Kruger et al., 2011). Natural selection favours those individuals that can employ the best strategy possible which will allow them to both survive and reproduce, in order to pass their genes along through their offspring (Griskevicius et al., 2011; Kruger et al., 2011). Successful reproduction ensures that an organism is able to pass on their lineage (Kruger et al., 2011). Simultaneously achieving both reproductive and survival success presents a resource allocation problem for organisms - there are limited resources available to any given organism and there is therefore implicit competition between reproductive and survival success (Figueredo et al., 2014). Life history theory has been developed in order to explain how and why 
Perceptions of Procedural Justice and Police Legitimacy: A Life History Perspective

organisms, including humans, assign their resources to different goals across the course of their life span (Griskevicius et al., 2011).

Life history theory asserts that organisms must distribute effort and resources across their somatic and reproductive development in ways that will best maximize their fitness (Kruger, et al., 2011). As mentioned, in order to do this species have to make trade-offs in how they allocate resources across their somatic and reproductive effort (Figueredo et al., 2005; Figueredo et al., 2014; Griskevicius et al., 2011; Kruger et al., 2011; Olderback, Gladden, Wolf \& Figueredo, 2014). Somatic effort refers to resources that are dedicated to the continual survival of an organism including growth, knowledge, and skills. Reproductive effort is those resources that are dedicated to the production and support of offspring. Reproductive effort can then be divided into mating effort and parental effort. Mating effort refers to resources dedicated to finding and retaining a sexual partner, which includes intrasexual competition, while parental effort refers to resources dedicated to developing and enriching the survival of offspring.

According to life history theory, the trade offs that an organism makes between somatic and reproductive effort are based upon two different life courses that species follow (Griskevicius et al., 2011). Life history strategies can be placed upon a continuum, with one end defined as a fast life history strategy ( $r$ - selected species), and the other end defined as a slow life history strategy $(K-$ selected species) (Durrant \& Ward, 2015; Griskevicius et al., 2011). Some species reflect selection for faster life history strategies while others reflect selection for slower life history strategies (Durrant \& Ward, 2015; Figueredo et al., 2005). For example, rabbits display rapid sexual development, show low levels of parental investment, have a shorter life span, and display low group cohesion. Rabbits therefore display a faster 
Perceptions of Procedural Justice and Police Legitimacy: A Life History Perspective

life history strategy. On the other hand, elephants display a slower life history strategy. Elephants have delayed sexual development, show higher levels of parental investment, have a longer life span, and display high group cohesion.

Humans generally fit closer to the $K$ end of the continuum and display slower life history traits (Durrant \& Ward, 2015; Olderback et al., 2014), however there is variability in life history traits displayed not only between species but also within species (Olderback et al., 2014). Humans demonstrate individual differences in the degree of slow life history strategy traits that they display, and where they sit on the life history strategy continuum (Griskevicius et al., 2011; Nettle, 2010; Olderback et al., 2014). Life history strategies can also shift over time (Griskevicius et al., 2011; Nettle, 2010; Olderback et al., 2014). The life history strategy of a human is not rigid; it can change over the course of an individual's life span. However, some research has noted that there are critical periods of development during the lifespan, which will influence the life history strategy that the individual will adopt (Ellis et al., 2012). For example, Jones (2009) has noted that early childhood is a particularly important time for the development of a life history strategy. This highlights the complex interplay between environment and genetics in the development of life history strategies. The diversity amongst human life history strategies means that they cannot be solely based upon genetics, although life history strategies may also have a genetic component (Durrant \& Ward, 2015; Wiebe, 2012).

Behaviours and traits, including earlier onset of puberty, risk-taking, impulsivity, anti-sociality, short-term thinking, less parental investment, having a larger number of children, and attainment of a larger number of sexual partners have been demonstrated to reflect a faster life history strategy (Figueredo et al., 2014; Wiebe, 2012). On the other end of the continuum, behaviours and traits such as a 
Perceptions of Procedural Justice and Police Legitimacy: A Life History Perspective

later onset of puberty, long-term thinking, cooperation, monogamy, high levels of parental investment, fewer children, and adherence to social rules have been shown to reflect a slower life history strategy (Figueredo et al., 2014; Wiebe, 2012). Table 1 illustrates a comparison between fast and slow life history strategies, where the differences between behaviours and traits associated with each strategy can be seen. Overall, a faster life history strategy devotes more resources towards reproductive effort over somatic effort and more resources to mating effort over parental effort. On the other hand, a slower life history strategy devotes more resources to somatic effort over reproductive effort and more resources to parental effort over mating effort. It is, however, important to emphasize that life history strategies and each of their respective traits can be placed upon a continuum, and they are not distinct separate typologies. For example, an individual can sit somewhere in the middle of the continuum and display a varying degree of life history strategy traits.

Table 1

Comparison of faster and slower life history strategies.

\section{PHYSIOLOGY}

$\begin{array}{lll}\text { Rates of development } & \text { Slower } & \text { Faster } \\ \text { Onset of puberty } & \text { Later } & \text { Earlier } \\ \text { Biological aging } & \text { Slower } & \text { Faster } \\ \text { MATING } & & \\ \text { Sexual debut } & \text { Later } & \text { Earlier } \\ \text { Sexual partners } & \text { Less } & \text { More }\end{array}$


Perceptions of Procedural Justice and Police Legitimacy: A Life History Perspective

$\begin{array}{lll}\text { Relationships } & \text { Pair-bond }\end{array}$

PARENTING

Age of reproduction Later Earlier

Number of offspring $\quad$ Fewer $\quad$ More

Investment in offspring Higher Lower

ECONOMIC PSYCHOLOGY

Time horizon Long Short

Immediate gratification Delay Seek

Risk losses for big gain Avoid Take

Ellis et al. (2012), Figure 7.1.

The Adaptive Calibration Model - The Development of Human Life History Strategies

One influential model used to explain the development of human life history strategies is the Adaptive Calibration Model (ACM), which was developed by Ellis, Del Guidice, and colleagues (Ellis et al., 2012). The ACM asserts that there are “inflection points" in individuals' lives (Ellis et al., 2012). These are key stages in an individuals' development where the person make shifts in their life history in response to dominant life history conditions. These shifts are designed to align the behavioural strategy of the individual to suit the environment that they are likely to experience during adulthood. The model argues that there are three crucial parts of an individual's early developmental environment that influences this process (Ellis et al., 2012):

1) The availability of resources.

2) Extrinsic morbidity/mortality (harshness of the environment). 
Perceptions of Procedural Justice and Police Legitimacy: A Life History Perspective

\section{3) Unpredictability.}

For an individual who grows up in an unpredictable environment where there are cues of extrinsic mortality, such as high rates of violence and death, a faster life history is likely to emerge. In comparison, an individual who grows up in a predictable and stable environment with an abundance of resources is likely to develop a slower life history.

From an evolutionary perspective, the ACM explains that in circumstances when the environment indicates cues of premature mortality, or cues that indicate the instability of the future, it is beneficial for females to adapt a life history strategy that is characterized by earlier onset on puberty and sexual debut, and for males to adapt a life history strategy that is characterized by increased risk taking, intrasexual competition, and mating effort (Ellis et al., 2012). In sum, human life history strategies are developed to increase the chances of successful reproduction in environments where the future is unpredictable, and chances of earlier mortality are likely.

It is important to note that the ACM states that humans do not consciously modify their life history strategy to suit the main features of their environment. The model argues that the stress response system (SRS) plays the main meditating role in the adjustment of human behaviour (Ellis et al., 2012). The human SRS includes three main physiological systems: the sympathetic nervous system, the parasympathetic nervous system, and the hypothalamus-pituitary-adrenal axis. The SRS monitors crucial information about the environment and adjusts the range of life history traits to match the environment. As Ellis et al. (2012, p. 600) explain:

The evolutionary model posits that natural selection shaped human neurobiological mechanism to detect and respond to the fitness-relevant costs 
Perceptions of Procedural Justice and Police Legitimacy: A Life History Perspective

and benefits afforded by different environments. Most important, these responses are not arbitrary but function adaptively to calibrate developmental and behavioural strategies to match those environments... Thus, stressful environments do not so much disturb development as direct or regulate it towards strategies that are adaptive under stressful conditions.

In the case of a stressful environment, it is adaptive for an individual to follow a faster life history. In a stressful environment such as one that is unpredictable, or high in mortality cues, then it is adaptive for the individual to increase their competitive and risk taking behaviour in order to increase their chances of successful reproduction at an earlier age. It is important to note that when an individual faces extreme deprivation or stress, such as malnutrition, then they are likely to display a slower life history strategy (Ellis et al., 2012). Such individuals are likely to adapt a slower life history strategy because their resources are so limited that if they did not, then their chances of survival would be significantly decreased. In this case these individuals are likely to display slower growth and delayed reproduction (Ellis et al., 2012). If an individual lives in a stressful environment, but has adequate resources and nutrition to grow and survive, then they are more likely to adapt a faster life history strategy (Ellis et al., 2012).

\section{Characteristics of Fast and Slow Life History Strategies}

Rushton (1985) argued that individuals who have a slower life history have a greater tendency for complying with rules and authority figures. Those with a slow life history have typically grown up in environments where resources and personal safety are reliable, and there is a well-established social structure, which relies on individuals following rules and maintaining social stability (Bogaert \& Rushton, 1989; Kruger \& Nedelec, 2014). Those with a slow life history therefore have a 
Perceptions of Procedural Justice and Police Legitimacy: A Life History Perspective

convergence of interests with authority figures who aim to enforce social norms and uphold social stability (Kruger \& Nedelec, 2014). As mentioned, the police are more likely to activate internal voluntary feelings of co-operation and compliance from people if the public feel they can relate to the police and their actions. It can be argued, then, that those with a slow life history are therefore more likely to feel they can relate to the norms and actions of the police force because both the police and individuals with a slow life history desire to maintain social order. Given that those with a slow life history benefit from upholding social stability, they rely on the police and the law to do this and therefore are more likely to have a positive perception of police legitimacy and procedural justice.

A slow life history is also associated with a high level of general altruism, and high levels of mutualistic social strategies (Figueredo et al., 2014; Olderback, Gladden, Wolf \& Figueredo, 2014). People who demonstrate mutualistic social strategies tend to show cooperation with others that they feel also show cooperative social strategies, and are more likely to believe their interests are consistent with the interests of others (Figueredo et al., 2014). Those with a slow life history are therefore more likely to believe that the police are worthy of compliance and cooperation because they are working in the best interests of society to preserve social order and stability.

Individuals with a faster life history have typically grown up in environments where there is a greater variation in mortality rates, personal safety and reproductive success (Kruger \& Nedelec, 2014). Those with a faster life history demonstrate a higher mating effort and have more competition amongst others for status and mates (Kruger \& Nedelec, 2014). Those with a fast life history are therefore likely to see authority figures, including the police, as competition for status and resources, as 
Perceptions of Procedural Justice and Police Legitimacy: A Life History Perspective

opposed to a group focused on maintaining a justified fair society (Kruger \& Nedelec, 2014). It can be argued then that those with a faster life history do not feel an internal obligation to cooperate and comply with the police because they feel as if they are in competition with them and need to act accordingly. This would mean those with a faster life history would show decreased levels of compliance and cooperation with the police. This would arguably lead to a decreased perception of police legitimacy and procedural justice because there would be less of a convergence with the interests of authority figures. Those individuals who demonstrate a faster life history also tend to demonstrate more antagonistic social strategies, and show less overall altruism (Figueredo et al., 2014; Olderback, Gladden, Wolf \& Figueredo, 2014). People who show antagonist social strategies are less likely to form cooperative relationships with others, and are more likely to defect and refrain from forming cooperative relationships (Figueredo et al., 2014).

\section{Summary}

Evolutionary theories have typically been neglected in criminology, however, the current study aims to demonstrate how life history theory is relevant to advancing our understanding of attitudes towards the police. Although there is a genetic component to life history strategies, life history theory does not undervalue the importance of the environment. The environment is a crucial aspect of the theory. Life history theory considers how individuals allocate their resources across their lifespan based on the type of environment that they are likely to reside in. Individual life history strategies can be placed upon a continuum between slow and fast life histories (Durrant \& Ward, 2015). It is important to reiterate that life history strategies are on a continuum; they are not two distinct and separate concepts. Different environmental 
Perceptions of Procedural Justice and Police Legitimacy: A Life History Perspective

conditions cause different life history strategies to emerge. A faster life history denotes more resources to reproductive effort and mating effort while a slower life history denotes more energy to somatic effort and parental effort. The various characteristics of different life history strategies are adaptive features that provide an individual with the best chance to survive and reproduce in the developmental conditions that they face, and the environment in which they reside.

\section{Life History Theory and Attitudes Towards the Police}

Based on the current research on life history theory, the following section will aim to explain how life history theory can account for the relationship that has been shown between attitudes towards the police and individual factors including ethnicity, gender, age, socio-economic status and neighbourhood characteristics.

\section{Ethnicity}

Studies have repeatedly shown that most members of ethnic minority groups tend to hold less favourable attitudes towards the police and have lower trust and confidence in the police compared to members of non-minority ethnic groups (Chow, 2012; Correia, Reisig \& Lovrich, 1996; Schafer, Heubner \& Bynum, 2003; Schuck et al., 2008; Sunshine \& Tyler, 2003a; Weitzer, 1999; Weitzer \& Tuch, 2004). Members of ethnic minority groups tend to be disproportionality situated in more unpredictable environments (Chow, 2012; Schafer et al., 2003), and it is therefore more likely that they will have a faster life history strategy. Research from America has shown that members of ethnic minority groups are more likely to have negative encounters with the police (Correia et al., 1996), and that African Americans are more likely to feel angry or upset after an encounter with the police and feel that they have been treated 
Perceptions of Procedural Justice and Police Legitimacy: A Life History Perspective

in a procedurally unjust way (Weitzer \& Tuch, 2004). Given it is more likely that ethnic minorities will have a faster life history strategy, they are more likely to feel that they are in competition with the police for status and resources, and that the police pose a threat to them. This would therefore make members of ethnic minority groups less likely to cooperate with the police.

Research in America has shown that African Americans are less likely to cooperate with the police (Vicki, Eller \& Abrams, 2006). A fast life history is associated with antagonist social strategies (Figueredo et al., 2014; Olderback, Gladden, Wolf \& Figueredo, 2014), and members of ethnic minorities are therefore less likely to form a cooperative relationship with the police or feel any obligation to cooperate with the police. As members of ethnic minority groups are more likely to live in unpredictable environments, then it can be argued that they are more likely to work for their own interests as opposed to working towards a stable group society, because they are less likely to have stability in their own individual lives. Legitimacy requires a willingness to co-operate with the police because they are seen as an organization that are trusted to enforce laws which are serving the best interests of all people in society (Gau, 2014). Ethnic minorities with a fast life history strategy are likely to be situated in an environment where there is a greater variation in mortality rates, personal safety, and reproductive success (Kruger \& Nedelec, 2014). It can be argued that this leads to more negative perceptions of police legitimacy because members of ethnic minority groups feel the police are not serving their community adequately given their safety, mortality, and reproductive success cannot be guaranteed.

Prior research has demonstrated that Māori in New Zealand are likely to have more negative attitudes of police legitimacy and procedural justice than their non- 
Perceptions of Procedural Justice and Police Legitimacy: A Life History Perspective

minority ethnic counterparts (Te Whaiti \& Roguski; Quince, 2007). Quince (2007) has shown that Māori are more likely to be disproportionally situated in neighborhoods that have a higher crime rate, and that they are more likely to be victims of crime. Māori are more likely to be situated in neighborhoods where there is instability surrounding their safety, mortality and reproductive success. Māori are therefore more likely to have a faster life history and are less likely to feel an obligation to cooperate or comply with the police. Since Māori are more likely to be a victim of a crime, they are more likely to view the police as illegitimate and as procedurally unjust, particularly because they tend to believe the police treat them unfairly. Quince (2007) also showed that Māori are more likely to base their opinions of the police around their family members opinions of the police, even if they have not had any prior contact with the police. Given that Māori are more likely to be situated in unpredictable environments then it is likely their family members would also follow a faster life history strategy. This would arguably decrease their perceptions of police legitimacy and procedural justice because their family's norms and values may not necessary align with the norms and values of the police.

Previous research has shown that there are individual differences in attitudes towards the police both between ethnicities and within ethnicities (Ho, Cooper and Rauschmayr, 2006; Skogan, 2005; Weitzer, 1999). Life history theory can be used to explain this finding. Those ethnic minorities that are situated in stable environments would be more likely to have a slower life history, and would therefore be more likely to have a positive opinion of police legitimacy and procedural justice. Members of ethnic minority groups who have a slower life history are more likely to have secure resources and a greater sense of personal safety (Kruger \& Nedelec, 2014). Thus those with a slower life history will benefit from following the law and upholding 
Perceptions of Procedural Justice and Police Legitimacy: A Life History Perspective

social stability in order to maintain their own sense of stability. Research has shown that perceptions of police legitimacy are dependent on whether an individual feels that they can relate to the police (Tyler 2004; Tyler, 2008), and those who follow a slower life history are arguably more likely to feel that the police share their norms and values. This can help to explain why there are within ethnicity differences regarding differences in perceptions of police legitimacy and procedural justice - not every member of an ethnic minority group will be situated in an unstable environment, nor will every member of an ethnic minority group have a faster life history strategy.

\section{Age}

An extensive amount of research has shown that younger people have more negative opinions of the police than older people do (Brown \& Benedict, 2002; Chow, 2012; Hinds, 2007; Miller et al., 2004; Reisig \& Parks, 2000; Schafer et al., 2003; Weitzer, 1999). Studies have also discovered that adolescents and young adults report faster life history strategies than older individuals do (Ellis et al., 2012; Kruger et al., 2015; Schafer et al., 2003), which can account for the relationship typically found between age and attitudes towards the police. Given that younger people have a faster life history strategy they are less likely to feel they can relate to the norms and preferences of the police force. Research on how young people view their interactions with the police supports this argument. Hinds (2007) showed that young people tend to perceive their interactions with the police as if they are being 'picked on', and Devaney, Pehrson, Bryan \& Blaylock (2014) showed that younger people felt the police believed they were 'up to no good' even if they were not doing anything wrong. This research arguably shows that younger people are less inclined to feel that the police are representative of their norms, values and preferences thus leading to a more negative perception of police legitimacy and procedural justice (Tyler 2004; 
Perceptions of Procedural Justice and Police Legitimacy: A Life History Perspective

Tyler, 2008). If younger people feel that the police are picking on them, even when they believe are not doing not doing anything wrong, then they are more inclined to feel as if they are in competition with the police.

Research has shown that younger people also commit a disproportionate amount of crime (Durrant \& Ward, 2015), meaning that they come into more contact with the police. The age crime curve, which is a well-established finding within criminological literature, shows a peak in offending during adolescence and young adulthood (Daly \& Wilson, 1990). Research has shown that younger people are more inclined to take risks than older individuals and are more likely to act in an impulsive, anti-social manner (Nettle, 2010). Evidence has shown there is a peak in the socioemotional system at this time along, and the cognitive control system is not yet fully developed (Cauffman, Cavanagh, Donley \& Thomas, 2015; Smith, Chein \& Steinberg, 2013; Steinberg, 2007). The changes in these two systems in the brain lead to increased risk taking in adolescence (Cauffman et al., 2015; Smith et al., 2015; Steinberg, 2007), which contributes to an increase in criminal behaviour (Cauffman et al., 2015; Steinberg, 2007). This consequentially means young people will have more interactions with the police, and these interactions are likely to be perceived as illegitimate and procedurally unjust.

Research has also shown that young males in particular commit a large amount of crime (Durrant \& Ward, 2015). From a life history perspective, this can be attributed to the fact that male mating effort is at its highest during adolescence (Kruger \& Nesse, 2006). This reflects the fact that young males have a faster life history strategy, and means that males at this age are more inclined to be in competition with one another in an attempt to attract a mate. This also means young males will be more inclined to view the police as competition and will decrease the 
Perceptions of Procedural Justice and Police Legitimacy: A Life History Perspective

likelihood that they will voluntarily cooperate and comply with the police. Given that young people commit a disproportionate amount of crime then they are also more likely to have a higher number of involuntary contacts with the police, and research has shown that this is related to an increase in negative attitudes towards the police (Schafer et al., 2003). Young people are more likely to engage in risky behaviour, act more impulsively and anti-socially because they follow a faster life history strategy (Figueredo et al., 2014). This again means that younger people will come into more contact with the police. From an evolutionary perspective, a younger persons' tendency to have a negative perception of the police may be a normative, biologically driven process and not due to ignorance and irrationality (Steinberg, 2007).

\section{Gender}

Studies have typically shown that females hold more positive perceptions of the police, and are more likely to show support for the police (Brandt \& Markus, 2000; O’Connor, 2008; Stewart Morris and Weir, 2014; Sunshine \& Tyler, 2003a). Research has shown that females tend to report slower life histories than males (Kruger \& Nesse, 2006). Females on average have higher levels of parental investment and hence less variation in reproductive success (Ellis et al., 2012; Kruger \& Nesse, 2006; Kruger et al., 2015). Males have lower levels of parental investment and they are therefore able to have greater variation in reproductive success than females (Archer, 2009). The higher level of parental investment by females mean they are able to have less children overall (Campbell, 2002), and this means they have needed to place a greater amount of care into each child in order to ensure their reproductive fitness success. Given that females have so much more to invest in parenting than males do (from an evolutionary perspective), they are less likely to engage in risky behaviour and are more inclined to follow social rules and act 
Perceptions of Procedural Justice and Police Legitimacy: A Life History Perspective

cooperatively with authority figures. (Kruger and Nesse, 2006). Females are more likely to want to protect themselves and their offspring, and will therefore share a convergence of interests with authority figures who also aim to uphold social stability. This will therefore increase the likelihood that females will have an increased perception of police legitimacy and procedural justice (Tyler 2004; Tyler, 2008).

Campbell (2013) has shown that males demonstrate an overall lower fear of crime than females do. Natural selection has increased female's fear response to ensure they are more conscious about protecting their own life and not placing themselves in risky situations that could ultimately be detrimental to their reproductive fitness (Campbell, 2013). This means that females are less likely to commit crime than males are (Durrant \& Ward, 2015) and are therefore less likely to come into contact with the police. This will lead to a more positive perception of police legitimacy and procedural justice. From an evolutionary perspective females have more to lose in terms of reproduction than males do (Campbell, 2013), which arguably means they will place more trust and confidence in the police to protect themselves and their offspring from harm. This is likely to increase the chance that females will cooperate and comply with the police, and feel a voluntary obligation to do so.

\section{Socio- Economic Status}

Prior research has shown that those who are of a low socio-economic status (SES) are likely to have more negative perceptions of the police (Brown \& Benedict, 2002; Chow, 2012; Nettle, 2010; Scaglion \& Condon, 1980; Schafer et al., 2003, Sunshine \& Tyler, 2003a; Sunshine \& Tyler, 2003b). Chow (2012) and Rushton (1985) have demonstrated that a slower life history is also associated with a higher socio-economic status, and a faster life history is associated with a lower socio- 
Perceptions of Procedural Justice and Police Legitimacy: A Life History Perspective

economic status. Rushton (1985) argued that those in a low socio-economic status area adopt a faster life history strategy and those in a higher socio-economic status area adopt a slower life history because of individual differences in the predictability of their environments. Those situated in a lower SES area tend to face an unstable environment and therefore have less predictability in their cues of safety, mortality, and reproductive success. This leads those in a low SES area to be more inclined to take more risks, focus on the short-term, and look for immediate gratification (Kruger \& Nesse, 2006). This means those in a low SES area place less importance on maintaining the law, or in co-operating and complying with those who are enforcing the law, including the police.

Being situated in a lower SES area during childhood can lead to permanent changes in the stress response system, which can lead to the development of a fast life history strategy early on in a person's life (Ellis et al., 2009). A low SES childhood exposes children to harsh and unpredictable environments and children are likely to witness an increased number of job and residential changes, inconsistent resource and employment availability, increased parental stress over the availability of resources and jobs, and greater instability in household membership (such as the coming and going of parents and stepparents) (Griskevicius et al., 2011). Life history strategies can shift if the child moves to a more stable environment. However, Griskevicius et al. (2011) argue that once a child is sensitized to unpredictable environments and a fast life history, then if they are ever exposed to stressors again in their lifespan they are more inclined to redevelop a faster life history than those are who have grown up in a higher SES area. This has important implications for understanding individual differences in attitudes towards the police because studies have shown that perceptions of how individuals are treated during an encounter with the police will 
Perceptions of Procedural Justice and Police Legitimacy: A Life History Perspective

affect later beliefs about the police and behaviours towards the police (Hinds \& Murphy, 2007; Mazerolle et al., 2013; Sunshine \& Tyler, 2003; Tyler, 2006). Growing up in a lower SES area, and having a faster life history strategy during childhood, could therefore predispose an individual to viewing the police as illegitimate and procedurally unjust for the remainder of their lifespan.

\section{Neighbourhood Characteristics}

An increasing amount of research has suggested that neighbourhood context plays an important role in determining attitudes towards the police (Hinds \& Murphy, 2007; Mazerolle et al., 2013; Sunshine \& Tyler, 2003; Tyler, 2006). Research has found that as crime rates in a neighbourhood increase, satisfaction with the police decrease (Reisig \& Parks, 2000). Those with a faster life history strategy are more likely to be situated in unpredictable neighbourhoods (Kruger \& Nedelec, 2014) with a higher crime rate. Thus it can be argued that those with a faster life history strategy are likely to be less satisfied with the police.

Griskevicius et al. (2011) argues that environmental conditions play a large role in the development of life history strategies. Studies have shown there is strong relationship between cues of mortality and reproductive timing (Dunkel, Mathes \& Beaver, 2013; Griskevicius et al., 2011). A study by Wilson and Daly (1997), which examined reproductive timing in Chicago, found that the median age of a woman's first child was 27.3 years in the neighbourhoods with the highest life expectancies and was 22.6 years in the neighbourhoods with the lowest life expectancies. The same study also showed a very strong correlation between male life expectancy and the homicide rate $(r=-.88)$, indicating that as life expectancy decreased for males the rate of homicide increased. Higher violent crime rates have been shown to be associated 
Perceptions of Procedural Justice and Police Legitimacy: A Life History Perspective

with an earlier age of reproduction, even once SES has been controlled for (Griskevicius et al., 2011).

Wilson and Daly (1997) argued that cues indicating a short life would lead to the development of a faster life history strategy with less focus on the future. The mortality cues that an individual faces in their childhood environment appear to have a particularly strong influence on the development of their life history strategy. Those children who face more unpredictable mortality cues tend to have children earlier than those who have more stable cues of mortality, who tend to delay reproduction (Griskevicius et al., 2011). A study by Nettle (2010) in England showed that life history strategies vary considerably based on neighbourhood conditions of deprivation. In neighbourhoods where conditions were the worst females had children earlier, birth weights were lower and fathers were more likely to be absent from their children's lives. The findings from these studies highlight the importance of neighbourhood conditions on the development of life history strategies.

Kruger, Munsell and French-Turner (2011) have demonstrated that living in a neighbourhood with visible signs of deterioration, including violent crime and abandoned buildings, leads to an increased stress response in individuals living in these areas. These individuals are likely to display a heightened state of alarm and vigilance, and feel more threatened by others in their neighbourhood. People living in deteriorating neighbourhoods are more likely to see others in the neighbourhood as a direct threat for resources and status and are more likely to feel as if they are in competition with others. This is consistent with life history research, which argues that those with a faster life history are more likely to see the police as competition for status and resources (Kruger \& Nedelec, 2014), therefore decreasing the likelihood that they will cooperate and comply with the police. 
Perceptions of Procedural Justice and Police Legitimacy: A Life History Perspective

Research has shown that living in an unpredictable environment leads to an increase in risk taking behaviour and a tendency to focus on a short-term outlook (Kruger \& Nesse, 2006; Kruger \& Nedelec, 2014). If the police were to try and prevent these individuals from engaging in risky behaviour, this could be viewed as unjust, and lead those with a faster life history to develop a negative opinion toward police legitimacy and procedural justice. Given that individuals with a fast life history are likely to live in more unpredictable neighbourhoods, then they may perceive risk taking and crime as justified because their own safety and mortality is not guaranteed. Such individuals will also tend to focus on a short-term outlook and may not consider the long-term effects of risky behaviour and criminal activity.

\section{Summary}

The current research has argued that life history theory can be valuable in explaining individual differences in perceptions of the police. Simply relying on demographic factors to explain attitudes towards the police has often produced conflicting results, and has failed to explain why and how these attitudes arise. Life history theory allows us to see how both distal and proximate features work together in order to explain human behaviour, and allows us to examine how and why different attitudes towards the police originate. Humans have evolved like any other species and our behaviour and thought processes, including our attitudes towards the police, cannot help but be shaped by this process of development (Durrant \& Ward, 2011).

\section{Previous Research Examining the Link Between Life History Strategy and}

\section{Attitudes Towards Police}

To date, there has only been one other study examining the relationship between life history strategy and perceptions of procedural justice and police legitimacy. Kruger, Nedlec, Reischl \& Zimmerman (2015) recently conducted a study with 1069 
Perceptions of Procedural Justice and Police Legitimacy: A Life History Perspective

participants in Michigan, United States of America that analysed the extent to which life history predicted perceptions of procedural justice and police legitimacy. The researchers used the Census Tracts to randomly select their participants, and sent out letters inviting participants to take part in the study. Participants could complete a hard copy of the survey and post it back, complete the survey online, or complete a computer-aided telephone interview. Kruger et al. (2015) employed scales to measure procedural justice, police legitimacy, an overall global attitude toward the police, and life history theory. The researchers also used four demographic items as control variables - gender, age, ethnicity, and level of educational attainment.

This study found that gender, age, and educational attainment were significantly associated with life history strategy; females, older individuals and those with a higher level of educational attainment were more likely to display a slower life history strategy. Ethnicity was not uniquely associated with life history strategy in this study. Although gender, age, and educational attainment were significantly associated with a slower life history, these demographic factors not did explain the relationship between life history and police attitudes. After conducting regression models, the study found that a slower life history strategy uniquely predicted greater perceptions of police legitimacy and procedural justice.

Kruger et al. (2015) also conducted a post hoc analysis to assess whether the association between life history strategy and attitudes towards the police could be explained by previous criminal experience or contact with the police. The relationship between life history and perceptions of procedural justice, along with the relationship between life history and perceptions of police legitimacy, remained significant regardless of previous criminal experience or contact with the police. Overall, results from this study showed that a slower life history strategy was the strongest predictor 
Perceptions of Procedural Justice and Police Legitimacy: A Life History Perspective

of positive perceptions of procedural justice, police legitimacy, and overall positive attitudes towards the police.

\section{The Current Study}

As an extension of an international study (Kruger et al., 2015), the main aim of the current research is to examine whether slower life history will predict more favourable attitudes towards the police (procedural justice), and greater willingness to collaborate and interact with the police (police legitimacy) within a New Zealand context. Based on existing life history research, the current research expects specific demographic characteristics to predict certain scores on life history measures. Females have a large investment in each of their offspring - they have a lower potential reproductive ability than males and higher levels of parental investment (Campbell, 2013). Therefore it is expected that females will report slower levels of life history strategies than males will (Kruger \& Nesse, 2006). Research has shown that younger people show faster life history strategies than older people do (Ellis et al., 2012; Kruger et al., 2015; Schafer et al., 2003), and consequently it is expected that in the current study younger people will report faster measures of life history strategy than their older counterparts. Given that members of ethnic minority groups tend to be disproportionality situated in more unpredictable environments (Chow, 2012; Schafer et al., 2003) it is expected that ethnic minorities in New Zealand will report faster life histories. A visual representation of the current study is shown in Figure 1, along with the main hypotheses, showing how distal and proximate features work together to cause different life history strategies to develop, thus lead to differing perceptions of the police.

Therefore, the current study hypothesizes that: 
Perceptions of Procedural Justice and Police Legitimacy: A Life History Perspective

1) Female respondents will report slower life history strategies than males.

2) Older respondents will report slower life history strategies than younger respondents.

3) Members of ethnic minority groups in New Zealand, who tend to be disproportionally situated in more unpredictable environments, will report faster life history strategies than members of non-minority ethnic groups.

4) Those of a lower socio-economic status will report faster life history strategies than those of a higher socio-economic status.

These demographic characteristics will be included in order to test the central hypotheses:

5) That slower life history will predict more favourable attitudes towards the police, such as higher levels of trust and fairness (procedural justice), within a New Zealand context, after controlling for age, gender, socioeconomic status, ethnicity, prior police interaction, and prior arrest.

6) That slower life history will predict a greater willingness to collaborate with the police, such as greater likelihood to report a crime to the police or interact with them outside of reporting a crime (police legitimacy), within a New Zealand context, after controlling for age, gender, socio-economic status, ethnicity, prior police interaction, and prior arrest.

7) That slower life history will predict more favourable perceptions towards police socialization, within a New Zealand context, after controlling for age, gender, socio-economic status, ethnicity, prior police interaction, and prior arrest. 
Perceptions of Procedural Justice and Police Legitimacy: A Life History Perspective

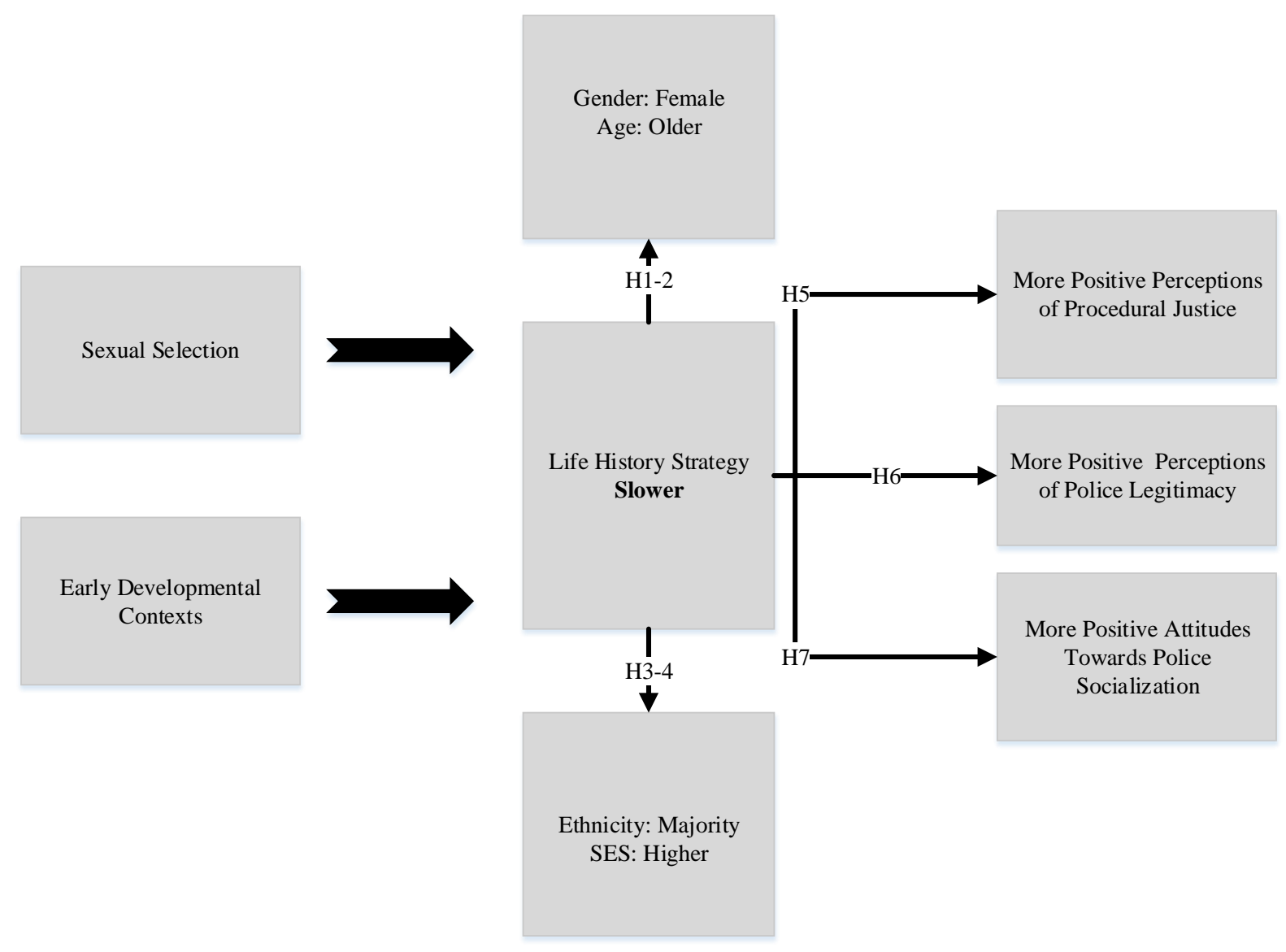

Figure 1

Distal and proximate features leading to individual differences in perceptions of procedural justice, police legitimacy, and police socialization. 
Perceptions of Procedural Justice and Police Legitimacy: A Life History Perspective

\section{Methods}

\section{General Overview}

In order to test the hypotheses, two studies were conducted. The first study used a student population from Victoria University of Wellington, and the second study used a general population from within the Wellington region. A quantitative research method was employed with the use of an online survey (see Appendix A) to collect data, which measured individual attitudes towards procedural justice and police legitimacy, along with individual life history strategies. As Newman \& Benz (1998) contended, a quantitative research approach is used when a study begins with a theory or hypothesis, and the researcher investigates for confirmation or disconfirmation of that theory or hypothesis. The current study stipulated several hypotheses that were being tested, and therefore it was logical to employ a quantitative approach. The current study used a cross-sectional survey design; the data from both study one and study two were collected from a chosen sample population in order to represent a wider population. An online survey was used in order to reach a wide, diverse sample population while ensuring anonymity and confidentially of all participants.

\section{Ethics}

Ethics approval was sought from the Victoria University Human Ethics Committee prior to the commencement of both study one and study two. The committee granted ethical approval for both studies on $12 / 08 / 2015$, with an amendment to study one granted on $12 / 10 / 2015$. Originally study one planned to recruit student participants solely through the use of their online learning page 
Perceptions of Procedural Justice and Police Legitimacy: A Life History Perspective

'Blackboard', however the response rate was lower than anticipated so study one expanded its participant recruitment to the use of social media.

Ethical implications were thoroughly considered for both studies, and steps were taken to limit any harm to participants. The use of an online survey ensured complete anonymity and confidentiality. Only participant's responses to the survey questions were recorded and all other information was discarded. Study two involved contacting members of the public from the Wellington region inviting them to take part in the online survey. No identifying information was collected from any of the participants. The participants in study two were recruited through the use of the electoral roll. Prior to obtaining an extract of the electoral roll, a letter was written to the electoral commission explaining what the extract would be used for, and how the public's information would be protected. The Vice Chancellor of Victoria University read and signed this letter. Members of the public also had the option of requesting a hard copy of the survey from my supervisor, Dr Russil Durrant, to manually fill out and post back. If a participant requested to manually fill out the survey and post it back, then it was ensured that they would not be identifiable in any way. Participants were provided with the contact details of my supervisor if they wanted to request a hard copy of the survey to ensure that I would not be able to identify participants in any way, and to ensure absolute anonymity of responses.

All results from the online survey were held in a password-protected file on the computer, and any hard copies were held in a locked file. Participants were advised that they needed to be 18 years of age or older to take part in the survey given the nature of the some of the questions, and due to the fact social media was being used in study one. A detailed participant information sheet was also provided at the beginning of the survey, which insured participants were fully informed about the 
Perceptions of Procedural Justice and Police Legitimacy: A Life History Perspective

study that they were taking part in. The information sheet also provided participants with an email address to contact if they were interested in receiving the results of the study, once they are available.

\section{Study 1}

Participants and Design. The study used a cross-sectional survey research design. There were originally 305 participants who completed the survey. Prior to analysing the data, any incomplete survey responses were deleted, as were any responses from participants who indicated they were under the age of 18 . This led to a total number of 235 participants being included in the final analysis. The final 235 participants were aged from $18-71(M=23.27, S D=7.83)($ Females $=68.9 \%$, Males $=31.1 \%)$.

Procedure. Qualtrics was used to generate the survey before participants were recruited through Victoria University of Wellington, and through the use of social media. A link to the survey was placed on the student's online learning page, 'Blackboard' of four criminology undergraduate courses (CRIM219, 216, 322, and 326), after obtaining permission from each of the course co-ordinators. The link was also placed on the social media website Facebook. The link was shared on student run Facebook pages associated with Victoria University ("Overheard at Vic" and "Vic Deals"), however these pages are not affiliated to Victoria University. At the beginning of the survey a participant information sheet was presented (see Appendix B) that explained the content of the survey, highlighted that participants could withdraw from the survey at any time without their responses being recorded, and that voluntary consent was implied through the completion of the survey. Participants were advised that they needed to be 18 years of age or over to complete the survey. 
Perceptions of Procedural Justice and Police Legitimacy: A Life History Perspective

At the end of the survey, links to support services were made available for participants in case the survey triggered any negative psychological responses.

Following the participant information sheet, demographic questions were asked including participants' age, gender, and ethnicity. Participants were provided with a blank space to write their ethnicity. Consequentially the responses were too varied to be included in the final data analysis. It was noted that the response option for ethnicity would need to be altered for the second study. After the initial demographic questions, participants were then asked to complete the scales that measured:

- Attitudes towards the dangerousness of the community where the individual spent the first 16 years of their life.

- Perceptions of procedural justice in the community where an individual spent the first 16 years of their life.

- Attitudes towards police legitimacy.

- Attitudes towards police socialization (willingly initiating contact with the police).

Participants were also asked if they had ever been arrested, whether the police had ever initiated an interaction with them in the community where they spent the first 16 years of their life, and whether the participant themselves had ever initiated an interaction with the police in the community where they spent the first 16 years of their life. Lastly participants were asked to answer the Mini K scale, which measured their individual life history strategy. All questions were answered on either a 5-point or 7-point likert scale, or with a "yes" or a "no" in the case of questions such as, "have you ever been arrested?" 
Perceptions of Procedural Justice and Police Legitimacy: A Life History Perspective

Materials. Multiple scales were used to measure individual attitudes towards the dangerousness of the community where they spent the first 16 years of their life, procedural justice in the community where they spent the first 16 years of their life, police legitimacy, and police socialization. Participants were asked about the first 16 years of their life due to the university sample being used in study one. The first 16 years of their life was likely to be more representative of their views and experiences, as they may have only been living in their current location for a short period of time. Each scale will be described below.

Community Dangerousness. Individual attitudes towards the dangerousness of the community where participants spent the first 16 years of their life was measured using a 4 item scale adapted from Kruger, Nedelec, Reischl \& Zimmerman (2015) $(\alpha=.861)$. Questions included, "Please think about the community where you spent most of the first 16 years of your life and rate how dangerous you consider it in terms of": 'The general crime rate', and 'The likelihood that you would be attacked or otherwise face physical violence'." Participants rated their responses on a scale ranging from $1=$ not dangerous at all to $5=$ very dangerous, with a higher value representing a higher perceived level of community dangerousness. Responses of the individual items in the scale were summed together to produce a total community dangerousness score, with higher scores representing a higher rate of perceived community dangerousness in the community where participants spent the first 16 years of their life. A community dangerousness scale was included as a representation of the perceived level of crime in the neighbourhood where participants grew up. It was therefore important to include this scale as a control measure.

Procedural Justice. Individual attitudes towards procedural justice in the community where participants spent the first 16 years of their life was measured using 
Perceptions of Procedural Justice and Police Legitimacy: A Life History Perspective

a 16 item scale adapted from Kruger et al. (2015) $(\alpha=.950)$. Participants were asked to answer each question on a scale ranging from $1=$ strongly disagree to $5=$ strongly agree. Questions included, "Please think about the where you spent most of the first 16 years of your life and the police in that community. Police in my community: 'Make decisions that are right for my community', 'Help prevent society from collapsing', and 'Explain their decisions to the people they deal with'. A number of procedural justice questions needed reverse coding during analysis so that $5=$ strongly disagree, as higher values represented stronger perceptions of procedural justice. Examples of such questions that needed reverse coding included: "Police in my community": 'Get social status from their jobs', and 'Like to show off'. All of the questions used to measure attitudes towards procedural justice have been previously shown in existing literature to formulate a reliable scale to measure the concept of procedural justice (Kruger et al., 2015). Responses of the individual items in the scale were summed together to produce a total procedural justice score, with higher scores representing a more positive perception of procedural justice.

Police Legitimacy. The scale that was used to measure individual attitudes towards police legitimacy was also adapted from Kruger et al. (2015) $(\alpha=.829)$. This was a 4 item scale and questions included: "I would contact the police": "To report a crime in my neighbourhood', and 'To report suspicious activity in my neighbourhood'. Participants rated their responses on a scale ranging from $1=$ strongly disagree to $5=$ strongly agree, again with higher values representing stronger perceptions of police legitimacy. Research has shown that those who believe the police are more legitimate are more likely to contact the police and rely on the police; therefore these questions were combined to be an overall measure of attitudes towards police legitimacy (Kruger et al., 2015). Responses of the individual items in the scale 
Perceptions of Procedural Justice and Police Legitimacy: A Life History Perspective

were summed together to produce a total police legitimacy score, with higher scores representing a more positive perception of police legitimacy.

Police socialization. Again, the scale used to measure individual attitudes towards police socialization was adapted from Kruger et al. (2015) $(\alpha=.744)$. This was a 3-item scale and questions included: "If you see a police officer walking towards you on the street, how likely would you be to": 'Say hello', 'Say hello back if the officer says hello to you', and 'Start an informal conversation'. Participants were asked to answer each question on a scale ranging from $1=$ very unlikely to $5=$ very likely. Research has shown that those who view the police as legitimate are more likely to initiate contact with the police, hence the inclusion of this scale. Responses of the individual items in the scale were summed together to produce a total police socialization score, with higher values indicating an increased willingness to initiate contact with the police.

Participants were also asked 3 further control questions to test whether their perspectives on police legitimacy, procedural justice and police socialization could be influenced by prior arrest experience or by prior police interaction.

Police interaction. Participants were asked the following two questions, "Did the police ever initiate an interaction with you in the community where you spent the first 16 years of your life?", and "Did you ever initiate an interaction with the police in the community where you spent the first 16 years of your life?". The responses to these questions were coded in SPSS as $1=$ yes and $2=$ no. These questions were reverse coded during analysis so that $1=$ no and $2=$ yes. This was done so that results were easier for the reader to interpret during later statistical analysis. Responses of the two individual questions were summed together to produce a total prior police interaction score $(\alpha=.730)$. A higher score indicated a greater degree of previous 
Perceptions of Procedural Justice and Police Legitimacy: A Life History Perspective

interaction with the police, while a lower score indicated a lesser degree of previous interacton with the police.

Prior arrest experience. Participants were also asked, "Have you ever been arrested?". The responses to this question was coded in SPSS as $1=$ yes and $2=$ no. Again, this question was reverse coded during analysis so that $1=$ no and $2=$ yes .

Lastly, the study employed the Mini-K scale (Figueredo et al., 2006) to measure the life history strategy of participants.

Mini-K scale. Individual life history strategies were measured using the MiniK scale $(\alpha=.818)$. Figueredo et al. (2005) originally created The Arizona Life History Battery (ALHB) based on the analysis of a large-scale study in the United States of America. The Mini-K scale is a 20-item short form version of The Arizona Life History Battery (ALHB), developed by Figueredo et al. (2006), and was designed with two to three items measuring each construct of the 199-item ALHB (Figueredo et al., 2014; Olderback et al., 2014). The Mini-K has been shown to be a direct measure of the latent K-factor that underlies the multiple convergent scales of the ALHB, and has been shown to provide a more global assessment of the K-factor (Figueredo et al., 2014). Previous studies have shown that the Mini-K scale correlates strongly with the full ALHB and additionally displays good construct and criterionrelated validity (Figueredo et al., 2014; Olderback et al., 2014). The 20-item Mini-K also considers the time constraints of participants. Participants were asked to answer questions including, "I often make plans in advance", "I am often in social contact with my blood relatives", and "I would rather have one than several sexual relationships at a time." Participants were asked to answer each question on a scale ranging from $1=$ strongly disagree to $7=$ strongly agree, with a higher score on the Mini-K scale indicating a slower individual life history. Responses of the individual 
Perceptions of Procedural Justice and Police Legitimacy: A Life History Perspective

items in the scale were then summed together to produce a total life history score, with a higher score representing a slower life history strategy.

\section{Analysis.}

Data from study one was analysed using SPSS version 23. Before the analysis was conducted, any incomplete survey responses were deleted from the data set as well as responses from participants under the age of 18 . In study 1 there was 3 demographic questions originally used as control variables - gender, age, and ethnicity. Gender was coded in SPSS as $1=$ male and $2=$ female. Age of participants was measured continuously in years. Ethnicity had to be excluded from the analysis as participants were provided a blank space to write their ethnicity, and responses were too varied to be included. Therefore in the final analysis, gender and age were used as the demographic control variables.

In order to test the hypotheses, a number of analytical steps were then conducted. Firstly, zero-order correlations were performed to see whether or not there were any significant associations between the study variables. Next, an independent samples t-test was carried out to analyse whether males and females differed in their life history strategy. Lastly, the study employed multiple regression models to assess the extent to which life history strategy predicted perceptions of procedural justice, police legitimacy, and police socialization after controlling for demographic and previous police interaction/prior arrest variables.

Prior to analysis a visual examination of the data was undertaken using box plots, stem and leaf plots, and normal Q-Q plots to assess for outliers and significant deviations from normality for all of the main variables. No outliers were removed from the dataset as a result of this analysis. All of the main variables violated assumptions of normality as revealed by significant outcomes for the Kolmogorov- 
Perceptions of Procedural Justice and Police Legitimacy: A Life History Perspective

Smirnov and Shapiro-Wilk's scores. Log transformations and square root transformations were undertaken on all the data. However, these transformations did not eliminate the violation of normality. Tests were run with and without transformed data generating the same pattern of significant results so untransformed data is presented throughout. For all regression analyses, an inspection of the variance inflation factors and tolerance statistics were undertaken to screen for violations of multicollinearity. No violations were uncovered in any of the regression models.

\section{Results}

The descriptive statistics (range, mean, and standard deviation) for all of the study variables are shown below in Table 2 . Within the final 235 participants included in the analysis, $68.9 \%$ were female and $31.1 \%$ were male. Also within the final sample, $93.6 \%$ of participants had not been arrested, and $6.4 \%$ indicated that they had been arrested in their lifetime.

Zero-order correlations between the study variables are shown in Table 3. A positive correlation was shown between gender and life history strategy, showing that being female was correlated with a slower life history strategy. Contrary to hypothesis two, that older respondents would report slower life histories than younger respondents, there was no correlation between age and life history. This finding can likely be attributed to the young sample used, as the average age of participants was 23.27 years. The Mini- K scale was positively correlated with procedural justice and police legitimacy, showing that a slower life history score was related to a higher procedural justice and police legitimacy score.

Furthermore, the community dangerousness measure was negatively correlated with procedural justice, police legitimacy, and police socialization. This finding indicates that as perceptions of community dangerousness increased, 
Perceptions of Procedural Justice and Police Legitimacy: A Life History Perspective

perceptions of procedural justice, police legitimacy, and the likelihood to initiate contact with the police decreased. This correlation is relevant to note as those with a faster life history tend to be situated in more dangerous communities, although interestingly life history and community dangerousness were not correlated in this sample.

Table 2

Descriptive statistics for all variables: Study $1(N=235)$

\begin{tabular}{lll}
\hline Variable & Range & Mean (SD) \\
\hline Mini K & $64-127$ & $103.37(13.83)$ \\
Community Dangerousness & $4-19$ & $7.28(3.02)$ \\
Procedural Justice & $20-80$ & $55.85(12.47)$ \\
Police Legitimacy & $4-20$ & $14.31(3.33)$ \\
Police Socialization & $3-15$ & $9.41(2.60)$ \\
Police Interaction & $2-4$ & $3.23(.794)$ \\
Age & $18-71$ & $23.27(7.83)$ \\
& & \\
\hline
\end{tabular}


Perceptions of Procedural Justice and Police Legitimacy: A Life History Perspective

Table 3

Zero-order correlations among the study variables: Study 1

(2) (3)

(4)

(5)

(6)

(7)

(8)

(9)

\begin{tabular}{|c|c|c|c|c|c|c|c|c|}
\hline (1) Mini K & & & & & & & & \\
\hline (2) Community & -.035 & & & & & & & \\
\hline dangerousness & & & & & & & & \\
\hline (3) Procedural justice & $.254 * *$ & $-.281 * *$ & & & & & & \\
\hline (4) Police legitimacy & $.298 * *$ & $-.300 * *$ & $.622 * *$ & & & & & \\
\hline (5) Police socialization & $.342 * *$ & $-.144 *$ & $.591 * *$ & $.613 * *$ & & & & \\
\hline (6) Police interaction & .081 & .048 & $.147 *$ & .081 & $.264 * *$ & & & \\
\hline (7) Prior arrest & .025 & -.057 & $-.173 * *$ & .082 & .055 & .076 & & \\
\hline (8) Gender (female) & $.256^{* *}$ & $.145^{*}$ & .044 & .124 & .022 & $.137 *$ & $.163^{*}$ & \\
\hline (9) Age & .100 & -.032 & -.057 & .086 & .027 & $.157 *$ & -.125 & .027 \\
\hline
\end{tabular}

${ }^{*} p<.05$ (two-tailed test); ${ }^{* *} p<.01$ (two-tailed test) 
Perceptions of Procedural Justice and Police Legitimacy: A Life History Perspective

In order to test the hypothesis that males would have a faster life history strategy than females an independent samples t-test was carried out. Consistent with hypothesis 1 , females scored significantly higher on the Mini K life history inventory $(M=105.78, S D=12.97)$ compared to males $(M=98.10, S D=14.42), t(232)=-$ 4.04, $p<.001, r=.26$. Thus female participants were shown to report a slower life history strategy than their male counterparts.

In order to test hypothesis 5,6 , and 7 concerning the relationship between life history strategy and procedural justice, police legitimacy, and police socialization three separate linear regressions were undertaken with life history score, community dangerousness, age, gender, police interaction, and experiences of prior arrest as predictor variables. The results of these regression analyses are shown in Tables 4, 5, and 6.

The results of the first regression supported the hypothesis that life history strategy would predict perceptions of procedural justice. Overall the six variables included in the model explained $18.9 \%$ of the variance $\left(R^{2}=.19, F(6,227)=8.84, p\right.$ $<.001)$. It was found that life history $(\beta=.23, p<.001)$, community dangerousness $(\beta$ $=-.27, p<.001)$, police interaction $(\beta=.16, p<.05)$, and prior experience of arrest $(\beta$ $=-.16, p<.05)$ all predicted perceptions of procedural justice. In other words, individuals with slower life history strategies had more favourable perceptions of police procedural justice as did those individuals who were more likely to have experienced police contact, whereas individuals who grew up in more dangerous communities and those that had experienced prior arrest had less favourable views of police procedural justice. 
Perceptions of Procedural Justice and Police Legitimacy: A Life History Perspective

The results of the second regression supported the hypothesis that life history strategy would predict perceptions of police legitimacy. Overall the six variables included in the model explained $19.8 \%$ of the variance $\left(R^{2}=.20, F(6,227)=9.34, p\right.$ $<.001)$. It was found that life history $(\beta=.24, p<.001)$, community dangerousness $(\beta$ $=-.30, p<.001)$, and police interaction $(\beta=.13, p<.05)$ all predicted perceptions of police legitimacy. In other words, individuals with slower life history strategies had more favourable perceptions of police legitimacy as did those individuals who were more likely to have experienced police contact, whereas individuals who grew up in more dangerous communities had less favourable views of police legitimacy.

The results of the third regression supported the hypothesis that life history strategy would predict willingness to initiate contact with the police (police socialization). Overall the six variables included in the model explained $20.3 \%$ of the variance $\left(R^{2}=.20, F(6,227)=9.61, p<.001\right)$. It was found that life history $(\beta=.32$, $p<.001)$, community dangerousness $(\beta=-.13, p<.001)$, and police interaction $(\beta=$ $.26, p<.05)$ all predicted perceptions of willingness to initiate contact with the police. In other words, individuals with slower life history strategies had more favourable perceptions towards police socialization as did those individuals who were more likely to have experienced police contact, whereas individuals who grew up in more dangerous communities had less favourable views towards police socialization. 
Perceptions of Procedural Justice and Police Legitimacy: A Life History Perspective

Table 4

Summary of linear regression analysis for variables predicting procedural justice:

Study 1

\begin{tabular}{llll}
\hline Variable & $\mathrm{B}$ & Std. Error & $\beta$ \\
\hline Life History & .21 & .06 & $.23 * * *$ \\
Community & -1.1 & .25 & $-.27^{* * *}$ \\
dangerousness & & & \\
Gender $(1)$ & -.41 & 1.7 & -.02 \\
Age & -.08 & .10 & -.05 \\
Prior police interaction & 2.5 & .98 & $.16^{*}$ \\
Prior arrest & -80 & 3.1 & $-.16^{*}$ \\
\hline$* p<.05 ; * * p<.01 ; * * * p<.0001$ & &
\end{tabular}

Table 5

Summary of linear regression analysis for variables predicting police legitimacy:

Study 1

\begin{tabular}{llll}
\hline Variable & $\mathrm{B}$ & Std. Error & $\beta$ \\
\hline Life History & .06 & .02 & $.24^{* * *}$ \\
Community & -.33 & .07 & $-.30^{* * *}$ \\
dangerousness & & & \\
Gender (1) & -.66 & .45 & -.09 \\
Age & .03 & .03 & .07 \\
Prior police interaction & .52 & .25 & $.13^{*}$ \\
Prior arrest & -.90 & .82 & -.07 \\
\hline
\end{tabular}

$* p<.05 ; * * p<.01 ; * * * p<.0001$

Table 6

Summary of linear regression analysis for variables predicting police socialization:

Study 1 
Perceptions of Procedural Justice and Police Legitimacy: A Life History Perspective

\begin{tabular}{llll}
\hline Variable & $\mathrm{B}$ & Std. Error & $\beta$ \\
\hline Life History & .06 & .012 & $.32^{* * *}$ \\
Community & -.12 & .05 & $-.13^{*}$ \\
dangerousness & & & \\
Gender (1) & -.14 & .36 & -.02 \\
Age & .01 & .02 & .04 \\
Prior police interaction & .86 & .20 & $.26 * * *$ \\
Prior arrest & -.74 & .65 & -.07 \\
\hline$* p<.05 ; * * p<.01 ; * * * p<.0001$ & &
\end{tabular}

\section{Summary}

Female participants were shown to report a slower life history than males, providing support for hypothesis 1 . Hypothesis 2 was found to be unsupported; there was no relationship between age and life history strategy. Given that a University sample was used in study 1 , the age of participants was skewed towards a younger age demographic and this therefore may be the reasoning behind this finding. Hypothesis 3 and hypothesis 4 were not measured in study 1 .

Hypothesis 5, that life history would predict perceptions of procedural justice, was supported. Individuals with a slower life history were shown to have more favourable perceptions of procedural justice. Life history was the second strongest predictor variable of perceptions of procedural justice.

Hypothesis 6, that life history would predict perceptions of police legitimacy, was supported. Individuals with a slower life history were shown to have more favourable perceptions of police legitimacy. Again, life history was the second strongest predictor variable of perceptions of police legitimacy.

Hypothesis 7, that life history would predict willingness to initiate contact with the police (police socialization) was also supported. Individuals with a slower life history were shown to have more favourable perceptions towards police 
Perceptions of Procedural Justice and Police Legitimacy: A Life History Perspective

socialization. Life history was the strongest predictor variable of perceptions towards police socialization.

\section{Study 2}

Participants and Design. The study used a cross-sectional survey research design. 75 participants completed the survey and all 75 participants were included in the final analysis. Participants were aged from $18-79(M=40.56, S D=16.95)$ $($ Females $=54.7 \%$, Males $=45.3 \%)$.

Procedure. Qualtrics was used to generate the online survey. Study two recruited participants from the general public around the Wellington region. Participants were sampled by using an extract of the New Zealand electoral roll, which was sourced from the Electoral Commission of New Zealand. Before the Electoral Commission provided an extract of the electoral roll, a letter was required explaining what the extract would be used for, the value of the current research, and how the public's identifying information would be protected (see Appendix C). The electoral roll extract was obtained on 29/02/16.

A stratified random sampling technique was employed in order to obtain a group of potential participants from the extract. First, a list of all the postcodes in the Wellington region (New Zealand Post, 2016) (Wellington city, Upper Hutt, Lower Hutt, and Porirua) was collected from the NZ post website. Then, school decile ratings were sourced from the Government education website (Ministry of Education, 2016). All school deciles for each respective postcode were collated, and an average school decile rating for each postcode was calculated. The average school decile of the area was used as it was deemed a representation of the average socio-economic status in each suburb. School deciles are created by the Government to reflect the 
Perceptions of Procedural Justice and Police Legitimacy: A Life History Perspective

socio-economic status of the community in which the school is located (Ministry of Education, 2016). School deciles range from 1, which represent the $10 \%$ of schools that have the highest proportion of students from low socio-economic status areas, to 10, which represent the $10 \%$ of schools that have the lowest proportion of students from low socio-economic status areas (Ministry of Education, 2016). Thus in the current study deciles ranging from $1-3$ represented low socio-economic areas, $3-7$ represented medium socio-economic areas, and $7-10$ represented high socioeconomic areas.

A randomizing formula was applied to the extract in exel, because the electoral roll was originally organized in alphabetical order. Once the extract was in a random order, the first 800 names were taken from the extract and put into a new spreadsheet. These 800 names were then sorted by postcode. 200 names were taken from low, medium, high socio-economic areas, which led to a total of 600 letters being sent out inviting individuals to take part in the study. There was one standard letter template written (see Appendix D); however each letter was addressed individually to the individual being invited to take part in the study. Participants were provided with the option of requesting a hard copy of the survey from my supervisor to fill out and post back. For those that requested a hard copy, a self-addressed and prepaid envelope was provided so the participant could post the survey back at no cost to them. The returning envelope was addressed to my supervisor, who checked the survey for any identifying information before passing the hard copy along to me.

As with study one, a participant information sheet was provided at the beginning of the survey (see Appendix E). Following the participant information sheet, participants were again asked a series of demographic questions. Participants were asked their age, gender, ethnicity, and their highest level of education attained. 
Perceptions of Procedural Justice and Police Legitimacy: A Life History Perspective

Following the issue found in study 1 with the variance of ethnicities provided, participants were provided with a number of options and they were asked to select the ethnicity they identify most strongly with: New Zealander/European, Māori, Asian, Pacific, Indian, and 'Other' (participants were given a space to enter their ethnicity if they selected 'other'). The highest level of education attained was included as a survey question as an indication of socio-economic status. Participants were again provided with a list of responses to select from for their highest level of education completed: high school or equivalent, certificate or equivalent, diploma, graduate diploma or certificate, bachelors degree, post graduate diploma or certificate, bachelors degree with honours, masters degree, doctorate/PHD, and 'other' (participants were provided with a space to enter their response if they selected 'other').

Following the demographic questions, the remainder of the study was identical to study 1. Participants were asked to complete the scales that measured measured individual attitudes towards the dangerousness of the community where they spent the first 16 years of their life, procedural justice in the community where they spent the first 16 years of their life, police legitimacy, and police socialization. Participants were also asked the same three control questions - if they had ever been arrested, whether the police had ever initiated an interaction with them in the community where they spent the first 16 years of their life, and whether the participant themselves had ever initiated an interaction with the police in the community where they spent the first 16 years of their life. Lastly participants were asked to answer the Mini K scale, which measured their individual life history strategy. All of the questions were again answered with on either a 5-point or 7-point likert scale, or with a "yes" or a "no". 
Perceptions of Procedural Justice and Police Legitimacy: A Life History Perspective

Materials. The same scales that were employed in study 1 were used to measure individual attitudes towards the dangerousness of the community where they spent the first 16 years of their life, procedural justice in the community where they spent the first 16 years of their life, police legitimacy, and police socialization. In accordance with study one, participants were again asked about their experiences in the first 16 years of their lives.

Community dangerousness. As with study 1, the survey used the 4-item scale adapted from Kruger, Nedelec, Reischl \& Zimmerman (2015) $(\alpha=.851)$ to measure attitudes towards the dangerousness of the community where participants spent the first 16 years of their life. Responses of the individual items in the scale were again summed together to produce a total community dangerousness score, with higher scores representing a higher rate of perceived community dangerousness in the community where participants spent the first 16 years of their life.

Procedural justice. Again, the survey in study 2 used a 16 item scale adapted from Kruger et al. $(2015)(\alpha=.940)$ to measure attitudes towards procedural justice in the community where participants spent the first 16 years of their life. It was again necessary for a number of procedural justice questions to be reverse coded during analysis so that $5=$ strongly disagree, as higher values represented stronger perceptions of procedural justice. Responses of the individual items in the scale were then summed together to produce a total procedural justice score, with higher scores representing a more positive perception of procedural justice.

Police legitimacy. Study 2 again used the 4-item scale adapted from Kruger et al. (2015) $(\alpha=.792)$ to measure attitudes towards police legitimacy. Responses of the individual items in the scale were again summed together to produce a total police 
Perceptions of Procedural Justice and Police Legitimacy: A Life History Perspective

legitimacy score, with higher scores representing a more positive perception of police legitimacy.

Police socialization. Finally, the same 3-item scale adapted from Kruger et al. (2015) ( $\alpha=.774$ ) was used to measure attitudes towards police socialization. Responses of the individual items in the scale were again summed together to produce a total police socialization score, with higher values indicating an increased willingness to initiate contact with the police.

Participants were again asked 3 further control questions to examine whether their perspectives on police legitimacy, procedural justice, and police socialization could be influenced by prior arrest experience or by prior police interaction.

Police interaction. Participants were asked the following two questions, "Did the police ever initiate an interaction with you in the community where you spent the first 16 years of your life?", and "Did you ever initiate an interaction with the police in the community where you spent the first 16 years of your life?". The responses to these questions were coded in SPSS as $1=$ yes and $2=$ no. These questions were reverse coded during analysis so that $1=$ no and $2=$ yes. Responses of the two questions were summed together to produce a total prior police interaction score $(\alpha=$ .617), with a higher score indicating a greater degree of previous interaction with the police.

Prior arrest experience. Participants were also asked, "Have you ever been arrested?" The responses to this question was coded in SPSS as $1=$ yes and $2=$ no. Again, this question was reverse coded during analysis so that $1=$ no and $2=$ yes

Lastly, the study again used the Mini-K scale (Figueredo et al., 2006) to measure the life history strategy of participants. 
Perceptions of Procedural Justice and Police Legitimacy: A Life History Perspective

Mini-K scale. Individual life history strategies were once again measured using the Mini-K scale (Figueredo et al., 2006) $(\alpha=.888)$. Responses of the individual items in the mini-K scale were summed together to produce a total life history score, with a higher score representing a slower life history strategy.

\section{Analysis}

The data from study two was analysed using SPSS version 23. There were 4 participants who requested a hard copy of the survey and posted it back, and these responses were entered manually. Study 2 used 4 demographic questions as control variables - gender, age, ethnicity, and highest level of education attained (which represented socio-economic status). Gender was coded in SPSS as $1=$ male and $2=$ female. Age of participants was measured continuously in years. In order to obtain a measure of ethnic minority status, participants were divided into two groups and coded in SPSS as $1=$ the non-minority group and $2=$ the minority group. This distinction is based on the method used by Murphy and Cherney (2011) during their research on cooperation with police in Australia. In the 2013 New Zealand Census, $74 \%$ of the population identified with at least one European ethnicity (Statistics New Zealand, 2015). Therefore any participants who identified as a New Zealander or European were considered a part of the non-minority ethnic group, and those who identified with another ethnic group were considered a part of the ethnic minority group.

Lastly, highest level of education attained was coded as $1=$ high school or equivalent, 2 = certificate or equivalent, $3=$ diploma, $4=$ graduate diploma or certificate, $5=$ bachelors degree, $6=$ post graduate diploma or certificate, $7=$ bachelors degree with honours, $8=$ masters degree, and $10=$ doctorate/PHD. Those who selected the 'other' option had their response coded to the equivalent category 
Perceptions of Procedural Justice and Police Legitimacy: A Life History Perspective

from the options listed above. For example, one respondent stated their highest level of educational attainment was trade certificate so this was coded in SPSS as a 2 (certificate or equivalent).

A number of variables in the procedural justice measure were then recoded so that all values were consistent with $1=$ strongly disagree and $5=$ strongly agree. The three control questions were also recoded so that all values were consistent with $1=$ no and $2=$ yes. New variables were then computed to represent the total score of each of the 6 scales - community dangerousness, procedural justice, police legitimacy, police socialization, prior police interaction, and Mini-K (life history). The 6 scales were then analysed for internal reliability. All of the scales were found to have a good to very good Cronbach alpha score, apart from the prior police interaction scale, which had a slightly lower than desired Cronbach alpha. However, this can be attributed to the fact that there are only 2 items in the scale.

In order to investigate the hypotheses, a number of analytical steps were then conducted. Firstly, zero-order correlations were performed to see whether or not there were any significant associations between the study variables. Next, an independent samples t-test was carried out to see whether males and females differed in their life history strategy. An independent samples t-test was also carried out to see whether the non-minority ethnic group and the minority ethnic group differed in their life history strategy. Finally, the study employed multiple regression models to determine the extent to which life history strategy predicted perceptions of procedural justice, police legitimacy, and police socialization after controlling for demographic and previous police interaction/prior arrest variables.

As for study one, prior to analysis a visual examination of the data was undertaken using box plots, stem and leaf plots, and normal Q-Q plots to assess for 
Perceptions of Procedural Justice and Police Legitimacy: A Life History Perspective

outliers and significant deviations from normality for all of the main variables. No outliers were removed from the dataset as a result of this analysis. Community dangerousness, police legitimacy, police socialisation, and police interaction all violated assumptions of normality. However, the police legitimacy variable was normally distributed, while the life history variable produced marginally significant results for the Kolmogorov-Smirnov test $(p=.098)$ and a significant result on the Shapiro-Wilk's test $(p=.033)$. In order to best facilitate comparison with the results for study 1 a decision was made to undertake all analyses with untransformed data. For all regression analyses, an inspection of the variance inflation factors and tolerance statistics were undertaken to screen for violations of multicollinearity. No violations were uncovered in any of the regression models.

\section{Results}

The descriptive statistics (range, mean, and standard deviation) for all of the study variables are shown below in Table 7 . Within the final sample, $54.7 \%$ of participants were female and $45.3 \%$ of participants were male. $77.3 \%$ of participants identified as New Zealander/European, 9.3\% as Māori, 5.3\% as Pacific Islander, 4\% as 'other', $2.7 \%$ as Asian, and $1.3 \%$ as Indian. Thus $78.7 \%$ identified as the nonminority ethnic group and $21.3 \%$ identified as the ethnic minority group. Also within the final sample, $97 \%$ of participants had not been arrested, and 3\% indicated that they had been arrested in their lifetime.

Zero-order correlations between the study variables are shown in Table 8 . Age, gender, and level of educational attainment (measure of SES) were all positively correlated with the Mini-K scale. Ethnicity was negatively correlated with the Mini-K scale. In other words, being a female, being of a younger age, and having a higher level of educational attainment were all correlated with a slower life history score. On 
Perceptions of Procedural Justice and Police Legitimacy: A Life History Perspective

the other hand, being a part of the ethnic minority group was correlated with a faster life history score. A positive correlation was also found between life history strategy and measures of police legitimacy, procedural justice, and police socialization, showing that a slower life history score was correlated with a higher procedural justice, police legitimacy, and police socialization score.

Table 7

Descriptive statistics for all variables: Study $2(N=75)$

\begin{tabular}{lll}
\hline Variable & Range & Mean (SD) \\
\hline Mini K & $65-133$ & $102.80(16.70)$ \\
Community Dangerousness & $4-15$ & $7.43(2.80)$ \\
Procedural Justice & $25-78$ & $55.04(10.70)$ \\
Police Legitimacy & $8-20$ & $15.00(2.92)$ \\
Police Socialization & $3-15$ & $10.24(2.73)$ \\
Police Interaction & $2-4$ & $2.61(.77)$ \\
Age & $18-79$ & $40.60(17.06)$ \\
Educational Attainment & $1-8$ & $4.15(2.50)$ \\
\hline
\end{tabular}


Perceptions of Procedural Justice and Police Legitimacy: A Life History Perspective

Table 8

Zero-order correlations among the study variables: Study 2

\begin{tabular}{|c|c|c|c|c|c|c|c|c|c|c|c|}
\hline & (1) & (2) & (3) & (4) & (5) & (6) & (7) & $(8)$ & (9) & (10) & (11) \\
\hline \multicolumn{12}{|l|}{ (1) Mini K } \\
\hline (2) Community & -.168 & & & & & & & & & & \\
\hline \multicolumn{12}{|l|}{ dangerousness } \\
\hline (3) Procedural justice & $.574 * *$ & $-.426 * *$ & & & & & & & & & \\
\hline (4) Police legitimacy & $.566 * *$ & $-.413 * *$ & $.636^{* *}$ & & & & & & & & \\
\hline (5) Police & $.528 * *$ & $-.269 *$ & $.627 * *$ & $.548 * *$ & & & & & & & \\
\hline \multicolumn{12}{|l|}{ socialization } \\
\hline (6) Police interaction & .068 & -.034 & .216 & $.272 *$ & $.286 *$ & & & & & & \\
\hline (7) Prior arrest & .223 & -.178 & .140 & .205 & .065 & $-.278^{*}$ & & & & & \\
\hline (8) Gender (female) & $.420 * *$ & -.053 & .165 & .129 & .081 & $-.245^{*}$ & $.261 *$ & & & & \\
\hline (9) Age & $.265 *$ & -.163 & .148 & .021 & $.289 *$ & .108 & -.151 & .081 & & & \\
\hline $\begin{array}{l}\text { (10) Educational } \\
\text { attainment }\end{array}$ & $.344 * *$ & .074 & $.246^{*}$ & .213 & .195 & -.061 & $.229 *$ & .118 & 0.12 & & \\
\hline $\begin{array}{l}\text { (11) Ethnicity } \\
\text { (minority) }\end{array}$ & $-.400 * *$ & $.343 * *$ & $-.446^{* *}$ & $-.371 * *$ & $-.406^{* *}$ & -.117 & -.166 & -.180 & $-.260 *$ & -.096 & \\
\hline
\end{tabular}

${ }^{*} p<.05$ (two-tailed test); ${ }^{* *} p<.01$ (two-tailed test). 
Perceptions of Procedural Justice and Police Legitimacy: A Life History Perspective

In order to test the hypothesis that males would have a faster life history strategy than females an independent samples t-test was carried out. Consistent with hypothesis 1 , females scored significantly higher on the Mini K life history inventory $(M=109.15, S D=14.45)$ compared to males $(M=95.15, S D=16.05), t(73)=-3.96$, $p<.001, r=.42$. Thus females were shown to have a slower life history strategy than males.

In order to test the hypothesis that the minority ethnic group would have a faster life history strategy than the non-minority ethnic group an independent samples t-test was carried out. Consistent with hypothesis 3, the ethnic minority group scored significantly lower on the Mini K life history inventory $(M=90.06, S D=17.41)$ compared to the non-minority ethnic group $(M=106.25, S D=14.84), t(73)=3.73, p$ $<.05$. Thus the ethnic minority group was shown to report a faster life history strategy than the non-minority ethnic group. However, given the limited number of participants who identified as belonging to an ethnic minority group, this result is limited in its generalization to the wider New Zealand population.

In order to test hypothesis 5,6 , and 7 concerning the relationship between life history strategy and procedural justice, police legitimacy, and police socialization three separate linear regressions were undertaken with life history score, community dangerousness, age, gender, SES, police interaction, and experiences of prior arrest as predictor variables. The results of these regression analyses are shown in Tables 9, 10, and 11 .

The results of the first regression supported the hypothesis that life history strategy would predict perceptions of procedural justice. Overall the eight variables included in the model explained $52 \%$ of the variance $\left(R^{2}=.52, F(8,64)=8.76, p<\right.$ 
Perceptions of Procedural Justice and Police Legitimacy: A Life History Perspective

$.001)$. It was found that life history $(\beta=.48, p<.001)$ and community dangerousness $(\beta=-.31, p<.001)$ both predicted perceptions of procedural justice. In other words, individuals with slower life history strategies had more favourable perceptions of police procedural justice whereas individuals who grew up in more dangerous communities had less favourable views of police procedural justice.

The results of the second regression supported the hypothesis that life history strategy would predict perceptions of police legitimacy. Overall the eight variables included in the model explained $52 \%$ of the variance $\left(R^{2}=.52, F(8,64)=8.87, p<\right.$ $.001)$. It was found that life history $(\beta=.50 p<.001)$ and community dangerousness $(\beta=-.31, p<.005)$ both predicted perceptions of police legitimacy. In other words, individuals with slower life history strategies had more favourable perceptions of police legitimacy as did those individuals who were more likely to have experienced police contact, whereas individuals who grew up in more dangerous communities and those who were of a younger age had less favourable views of police legitimacy.

The results of the third regression supported the hypothesis that life history strategy would predict perceptions of willingness to initiate contact with the police (police socialization). Overall the eight variables included in the model explained $42 \%$ of the variance $\left(R^{2}=.42, F(8,64)=5.67, p<.001\right)$. It was found that life history $(\beta=.44, p<.001)$ uniquely predicted perceptions of police socialization. In other words, individuals with slower life history strategies had more favourable perceptions towards police socialization.

\section{Table 9}

Summary of linear regression analysis for variables predicting procedural justice: Study 2 
Perceptions of Procedural Justice and Police Legitimacy: A Life History Perspective

\begin{tabular}{llll}
\hline Variable & $\mathrm{B}$ & Std. Error & $\beta$ \\
\hline Life History & .31 & .08 & $.48^{* * *}$ \\
Community & -1.2 & .37 & $-.31^{*}$ \\
dangerousness & & & \\
Gender (1) & -1.5 & 2.3 & -.07 \\
Age & -.04 & .06 & -.06 \\
Prior police interaction & 2.1 & 1.3 & .15 \\
Prior arrest & -.97 & 4.7 & -.02 \\
Educational attainment & .45 & .42 & .11 \\
Ethnicity $(2)$ & -3.8 & 2.6 & -.15 \\
\hline$* p<.05 ; * * p<.01 ; * * * p<.0001$ & &
\end{tabular}

Table 10

Summary of linear regression analysis for variables predicting police legitimacy:

Study 2

\begin{tabular}{llll}
\hline Variable & $\mathrm{B}$ & Std. Error & $\beta$ \\
\hline Life History & .09 & .02 & $.50^{* * *}$ \\
Community & -.33 & .10 & $-.32^{*}$ \\
dangerousness & & & \\
Gender (1) & -.31 & .61 & -.05 \\
Age & -.04 & .02 & -.20 \\
Prior police interaction & .94 & .36 & $.25^{*}$ \\
Prior arrest & .76 & 1.3 & .06 \\
Educational attainment & .08 & .11 & .07 \\
Ethnicity (2) & -.54 & .71 & -.08 \\
\hline
\end{tabular}

$* p<.05 ; * * p<.01 ; * * * p<.0001$

Table 11

Summary of linear regression analysis for variables predicting police socialization:

Study 2 
Perceptions of Procedural Justice and Police Legitimacy: A Life History Perspective

\begin{tabular}{llll}
\hline Variable & $\mathrm{B}$ & Std. Error & $\beta$ \\
\hline Life History & .07 & .02 & $.44 * *$ \\
Community & -.12 & .10 & -.12 \\
dangerousness & & & \\
Gender $(1)$ & -.66 & .63 & -.12 \\
Age & .02 & .02 & .11 \\
Prior police interaction & .73 & .37 & .20 \\
Prior arrest & .13 & 1.3 & .01 \\
Educational attainment & .06 & .12 & .05 \\
Ethnicity $(2)$ & -.95 & .74 & -.14 \\
\hline$* p<.05 ; * * p<.01 ; * * * p<.0001$ & &
\end{tabular}

\section{Summary}

Female participants were shown to report a slower life history than males, providing support for hypothesis 1 . Hypothesis 2, that older respondents would report slower life histories than younger respondents, was supported. Hypothesis 3, that members of an ethnic minority group would demonstrate a faster life history strategy was again supported. Lastly, hypothesis 4 , that those of a lower socio-economic status will report faster life history strategies than those of a higher socio-economic status, was also supported.

Hypothesis 5, that life history would predict perceptions of procedural justice, was supported. Individuals with a slower life history were shown to have increased perceptions of procedural justice. Life history was the strongest predictor variable of perceptions of procedural justice.

Hypothesis 6, that life history would predict perceptions of police legitimacy, was supported. Individuals with a slower life history were shown to have increased 
Perceptions of Procedural Justice and Police Legitimacy: A Life History Perspective

perceptions of police legitimacy. Life history was the strongest predictor variable of perceptions of police legitimacy.

Hypothesis 7, that life history would predict willingness to initiate contact with the police (police socialization). Individuals with a slower life history were shown to have increased perceptions towards police socialization. Again, life history was the strongest predictor variable of perceptions towards police socialization.

\section{General Discussion}

The current study aimed to investigate the extent to which life history indicators explained individual attitudes towards perceptions of police legitimacy and procedural justice. Prior research conducted by Kruger et al. (2015) found that a slower life history strategy was the strongest predictor of positive perceptions of procedural justice and police legitimacy. This finding remained significant regardless of participant's prior contact with the police and participant's prior criminal history. Kruger et al. (2015) also found that age, gender, and socio-economic status were significantly associated with life history strategy; older individuals, females, those of a higher socio-economic status were more likely to display a slower life history strategy. The current study hypothesised that these findings would be replicated within a New Zealand population sample. Additionally, prior research has shown that members of ethnic minority groups tend to be disproportionality situated in more unpredictable environments (Chow, 2012; Schafer et al., 2003). The current study therefore hypothesized that individuals' of an ethnic minority status in New Zealand would display a faster life history strategy. Importantly, while the current study expected to find a relationship between demographic factors (gender, age, ethnicity, 
Perceptions of Procedural Justice and Police Legitimacy: A Life History Perspective

and socio-economic status) and life history strategy, the overall aim of the study was to explore the extent to which life history strategy could explain perceptions of police legitimacy and procedural justice after controlling for demographic factors, prior police contact, and prior arrest.

\section{Demographic factors}

Hypothesis 1, that female respondents would report a slower life history strategy than males, was supported. In both studies, there was a significant difference between the life history strategy of male and female participants. Consistent with prior studies, (Ellis et al., 2012; Figueredo et al., 2005; Kruger \& Nesse, 2006; Kruger et al., 2015), females were shown to report a slower life history strategy than males. The slower life history strategy of females reflects their natural selection for a higher level of parental investment (Ellis et al., 2012; Figueredo et al., 2005; Kruger \& Nesse, 2006; Kruger et al., 2015). The current study argues that females are more likely to be conscious of potential risks and threats that could cause harm to them and their offspring. Females may therefore share a convergence of norms with the police in their quest to maintain social stability. Thus the slower life history strategy of females may in part explain why previous research (Brandt \& Markus, 2000; O’Connor, 2008; Stewart, Morris \& Weir, 2014; Sunshine \& Tyler, 2003a) has typically found that females hold more positive perceptions of the police than males do.

The current study found mixed results for hypothesis 2 , that older respondents would report slower life history strategies than younger respondents. In study 1 there was no relationship found between age and life history strategy. This lack of relationship was likely the result of the student population sample that was used. Most 
Perceptions of Procedural Justice and Police Legitimacy: A Life History Perspective

of the participants were of a similar age, and as a result study 1 did not have a large degree of variation amongst age of participants. Study 2 however, found that there was a significant relationship between age and life history strategy. The faster life history strategy of younger individuals reflects their natural selection for risk taking and their competitive nature at this age (Kruger \& Nesse, 2006; Nettle, 2010). Arguably this could partly explain why there is a peak in offending during adolescence and young adulthood, along with an increase in risk taking and impulsivity at this age (Steinberg, 2007). The faster life history strategy of younger individuals may in part explain why previous studies have found that those of a younger demographic hold more negative perceptions of the police than those of an older demographic (Brown \& Benedict, 2002; Chow, 2012; Hinds, 2007; Miller et al., 2004; Reisig \& Parks, 2000; Schafer et al., 2003; Weitzer, 1999).

Hypothesis 3, that those individuals who are ethnic minorities would demonstrate a faster life history strategy than those of the ethnic majority, was supported. This result differs from that of the Kruger et al. (2015) study, which found no relationship between ethnicity and life history strategy. Arguably because those of an ethnic minority status are more likely to be disproportionally located in unpredictable environments (Chow, 2012; Schafer et al., 2003), they have an increased chance of developing a faster life history strategy. They therefore may be more inclined to focus on the short term, take more risks, and feel less of a convergence of norms with those in society who enforce the law. The faster life history strategy of ethnic minority groups may in part explain why previous studies have found that those of an ethnic minority status hold more negative perceptions of the police (Chow, 2012; Correia, Reisig \& Lovrich, 1996; Schafer, Heubner \& Bynum, 2003; Schuck et al., 2008; Sunshine \& Tyler, 2003a; Weitzer, 1999; Weitzer 
Perceptions of Procedural Justice and Police Legitimacy: A Life History Perspective

\& Tuch, 2004). However, due to the limited number of responses from ethnic minority participants, the current study acknowledges that the strength of the current statistical finding is limited in its generalization to the wider population. Although ethnic minority status is associated with a number of factors that might influence attitudes towards the police, it cannot be dismissed that part of the relationship may arise from feelings of prejudice and bias towards ethnic minority groups from the police.

Hypothesis 4, that those of a lower socio-economic status would report faster life history strategies than those of a higher socio-economic status, was supported. The current study used educational attainment as a measure of socio-economic status. Those with a lower level of educational attainment were found to have a faster life history strategy, where as those with a higher level of educational attainment were found to have a slower life history strategy. This is consistent with the results from Kruger et al. (2015), who also found a positive correlation with level of educational attainment and a slower life history strategy. The faster life history strategy of those of a lower SES status reflects the instability of their environment and their resources, which may cause them to act more impulsively and focus on the short term. Their future outlook may not be stable and they therefore may be more inclined to focus on the present as opposed to the future. They again may share less of a convergence of norms with authority figures, such as the police. The slower life history strategy of those of a lower SES status may in part explain why prior research has found that those who are of a lower SES are likely to have more negative perceptions of the police (Brown \& Benedict, 2002; Chow, 2012; Nettle, 2010; Scaglion \& Condon, 1980; Schafer et al., 2003, Sunshine \& Tyler, 2003a; Sunshine \& Tyler, 2003b). 
Perceptions of Procedural Justice and Police Legitimacy: A Life History Perspective

Generally speaking, studies have shown that females, older individuals, those of an ethnic majority, and those of a higher socio-economic status tend to hold more positive perceptions of the police. While previous studies have found there is a relationship between demographic factors and attitudes towards the police, demographic factors alone have proved unable to provide a conclusive explanation of why there are individual differences in attitudes towards the police. The current research, and previous research (Ellis et al., 2012; Figueredo et al., 2005; Kruger \& Nesse, 2006; Kruger et al., 2015; Schafer et al., 2003), has shown that females, older individuals, those of a non-minority ethnic status, and those of a higher socioeconomic status tend to show a slower life history strategy. Therefore hypotheses 5, 6, and 7 expected to find that life history strategy would explain individual differences in perceptions of police legitimacy and procedural justice, after controlling for demographic factors.

\section{Attitudes Towards Police Legitimacy, Procedural Justice and Police}

\section{Socialization}

Hypotheses 5, 6, and 7 aimed to investigate the extent to which life history theory explained individual attitudes towards perceptions of police legitimacy, procedural justice, and police socialization after controlling for demographic factors. Hypotheses 5, 6, and 7, that life history would predict perceptions of procedural justice, police legitimacy and willingness to initiate contact with the police (police socialization) were supported. In study 1, life history theory and community dangerousness predicted individual attitudes towards police legitimacy, procedural justice and police socialization after controlling for age, gender, prior police interaction, and prior arrest. In study 2 life history theory and community 
Perceptions of Procedural Justice and Police Legitimacy: A Life History Perspective

dangerousness predicted individual attitudes towards police legitimacy, procedural justice, and police socialization after controlling for age, gender, ethnicity, socioeconomic status, prior police interaction, and prior arrest. This is consistent with the research conducted by Kruger et al. (2015), who also found that slow life history predicted greater perceptions of police legitimacy and procedural justice after controlling for demographic factors.

The findings of the current study demonstrated that individual life history theory had a crucial influence on determining individual attitudes towards police legitimacy and procedural justice. Overall, the current study showed that those with a slower life history strategy were more likely to hold positive perceptions of police legitimacy and procedural justice, where as those with a faster life history theory were more likely to hold negative perceptions of police legitimacy and procedural justice. The current study also found that individuals with a slower life history were shown to have increased perceptions towards police socialization.

\section{Prior Police Interaction and Prior Arrest}

The current study also measured individual attitudes towards police legitimacy and procedural justice after controlling for prior experiences of police interaction and prior arrest. Results showed that life history theory strongly accounted for individual attitudes towards the police regardless of whether the individual had experienced prior interaction with the police or whether the individual had previously been arrested. Previous literature on police legitimacy and procedural justice has demonstrated that the actual outcome of an interaction between the police and a member of the public does not affect their overall perception of the police (Skogan, 2005; Tyler, 1990; Tyler, 2004; Tyler and Huo, 2002). Studies have shown that 
Perceptions of Procedural Justice and Police Legitimacy: A Life History Perspective

whether people feel that the police have acted in a legitimate and procedurally just manner during an interaction is much more likely to affect their current and future perceptions of the police. Interestingly, the results of the current study showed that those who had experienced prior interaction with the police in their lifetime held more favourable attitudes towards police than those who had not experienced prior interaction with the police. Based on the previous studies that have been conducted, this finding suggests that people in New Zealand generally feel the police act in a legitimate and procedurally just manner during an interaction. This assertion is based on the results that previous interactions with the police lead to a more positive perception of the police. Those who had been arrested in the past did hold less favourable attitudes towards the police, but prior arrest only explained a small amount of variance in the individual differences of attitudes towards the police. In all models, life history theory explained the vast majority of the variance that was found. It should be noted, however, that only a very small percentage of participants had experienced prior arrest, which limits the generalizability of this finding.

\section{Community dangerousness and attitudes towards the police}

A number of researchers have begun to examine the effect of macro-level conditions, such as neighbourhood characteristics, on attitudes towards the police (Brown \& Benedict, 2002; Chow, 2012; Nettle, 2010; O’Connor, 2008; Reisig \& Parks, 2000; Schafer et al., 2003). The current study found that perceptions of community dangerousness while growing up influenced individual perceptions towards police legitimacy, procedural justice, and police socialization. Importantly, community dangerousness predicted attitudes towards the police independently of a common life history battery. More specifically as perceptions of community 
Perceptions of Procedural Justice and Police Legitimacy: A Life History Perspective

dangerousness increased, perceptions of police legitimacy and procedural justice decreased. This is an important finding as research has shown that those with a faster life history tend to be disproportionality situated in more dangerous and unpredictable environments (Kruger \& Nedelec, 2014), however in the current studies the life history measure and community dangerousness did not correlate. Thus in both studies life history and community dangerousness seemed to be independent predictors of individual differences in attitudes towards the police. The Mini-K is currently the standard psychometric measure of life history variance however in the current study, this measure did not seem to capture all of the meaningful variance in life history. This should be addressed in future studies that use the Mini-K scale, as there may be scope for revision and improvement to the scale to ensure all meaningful variance is captured.

\section{Life history traits and attitudes towards the police}

Rushton (1985) originally argued that those with a slower life history are more likely to comply with rules and authority figures. Kruger and Nedelec (2014) later supported this claim by arguing that those with a slower life are more likely to share a convergence of interests with authority figures in society. Kruger and Nedelec (2014) also argued that those with a faster life history are more likely to perceive authority figures as competition for status and resources. Research has shown that those with a slower life history are more likely to show cooperation, a higher level of general altruism, and a higher adherence to mutualistic social strategies (Figueredo et al., 2014). The results of the current studies found support for these assertions. Those with a slower life history were found to have a greater perception of police legitimacy and procedural justice. Those with a slower life history strategy were also more 
Perceptions of Procedural Justice and Police Legitimacy: A Life History Perspective

willing to contact the police, thus indicating a higher level of cooperation and confidence with the police. The police are responsible for enforcing the law, and maintaining social stability, and those with a slower life history were found to be more supportive of this, and more willing to work with the police to achieve this. This indicates that individuals with a slower life history are more likely to have a positive attitude towards complying with mutualistic social strategies.

While the majority of research has shown that there is a relationship between demographic factors and attitudes towards the police, other studies have found no relationship between demographic factors and attitudes towards the police (e.g. Brown and Bendict, 2002; Correia, Reisig \& Lovrich, 1996; Reisig and Parks, 2000; Scaglion \& Condon, 1980; Skogan 2005). There is also no general consensus over which demographic factor is most relevant in explaining individual differences in perceptions of the police. The application of a life history strategy can clarify these inconclusive results. In the current studies, demographic factors had no predictive power when life history and community dangerousness were included in the regression models. Research has shown that human life history strategy varies from person to person (Griskevicius et al., 2011; Nettle, 2010; Olderback et al., 2014). Not everyone who is female, of an older age, of the ethnic majority and of a higher socioeconomic status will display a slower life history. Life history theory is a continuum of traits (Durrant \& Ward, 2015) and each individual will sit at a different place on the continuum. Therefore, each individual will differ in the extent to which they display the specific traits associated with either a faster life history strategy or a slower life history strategy. Thus perceptions of police will differ for each individual based on their personal life history strategy. 
Perceptions of Procedural Justice and Police Legitimacy: A Life History Perspective

\section{The environment and attitudes towards the police}

The current study highlighted the importance of the environment in individual attitudes towards the police. Life history strategy shifts in response to the stability and predictability of an individual's environment (Kruger et al., 2015). Therefore, as Kruger et al. (2015) have argued, the development of policy that will work on stabilizing an individual's environment may increase public perceptions of police. This is not something the police can achieve alone, and would require collaboration from many different social agencies. The ACM model has asserted that the availability of resources, the harshness of the environment and the unpredictability of the environment are the three most crucial aspects of a person's early environment that will influence the development of their life history strategy. Thus this model provides further support for the need of social agencies that can work on stabilizing environments, particularly at critical points in an individual's development. If environmental conditions can be stabilized in these periods of development, this may increase the chance of people developing a slower life history and thereby increase the chance they will develop a positive attitude toward the police.

Tyler and Huo (2002), during a study with Oakland residents who were living in high crime areas, found that how the police treated people during an interaction accounted for more variance in attitudes towards police than variations in the quality of police performance. Tyler and Huo (2002) argued that when the police acted in a fair and respectful manner, as opposed to a command and control manner, attitudes towards the police became more favourable. The current study maintains that this is an important assertion that police should take into consideration, particularly when interacting with those individuals who are likely to have a faster life history strategy. 
Perceptions of Procedural Justice and Police Legitimacy: A Life History Perspective

From a life history theory perspective individuals with a faster life history tend to lack stability in their resources, future outlook, and chances for survival. They therefore are more inclined to take risks and have a short term thinking pattern (Ellis et al., 2012). Consequentially if the police act in a control and command manner, individuals with a faster life history strategy may be more likely to perceive this a threat, in an already unpredictable environment where there is competition for status and resources. This may then increase feelings of competition with anyone they perceive as a further threat to their status and resources, including the police. This may therefore decrease the likelihood that those with a faster life history will cooperate with the police and their policies.

\section{Limitations}

The current study aimed to assess the extent to which life history theory accounted for perceptions of police legitimacy and procedural justice, however, there were some limitations within the study. Firstly, the study had a reasonably small sample size and therefore cannot be considered representative of the population of New Zealand. Particularly in study 2, the response rate from participants was low. In study 2, the vast majority of participants identified as a New Zealander/European and only a small number identified as belonging to an ethnic minority group. Therefore the claims the current study made concerning the relationship between ethnicity and life history is limited in its validity and generalizability. There was also a lack of response from people of a lower socio-economic status in both studies, which limited the variation of life history strategies amongst the participants.

Study 1 was advertised on the Victoria University blackboard pages for a number of criminology papers, and on a student-run social media site. Therefore a 
Perceptions of Procedural Justice and Police Legitimacy: A Life History Perspective

number of participants had a criminology background, which may have influenced their responses. Given that a university student sample was used in study 1, participants would have had a similar demographic background. Ideally, participants would have had a wider variation in their life history strategies. The link that provided access to the survey in study 2 was also quite long and detailed, and this may have deferred some people from taking part in the study.

\section{Implications}

The results of this study have offered a new and unique contribution to current literature surrounding attitudes towards the police. This study, and its application of life history theory to understanding attitudes towards the police, is the first of its kind in New Zealand. It has provided an extension of the Kruger et al. (2015) study in a new social context, and has contributed to the broader understanding of how life history affects perceptions of the police. The current study has extended on current policing literature, which has focused solely on examining the relationship between demographic factors and attitudes towards the police. The study has offered a new explanation for the underlying reason why people have different attitudes towards the police, and why certain demographic factors are associated with individual differences in attitudes towards the police - an explanation that is missing in the current literature. The value of life history theory in criminological research should therefore be recognized, and applied more frequently as opposed to being discounted.

The current study contributes to the current literature by providing an adaptive explanation for why prior studies have found a relationship between attitudes towards the police and demographic factors. Life history theory provides a deeper rationale for explaining individual differences in attitudes towards the police. The theory shows 
Perceptions of Procedural Justice and Police Legitimacy: A Life History Perspective

how proximate and distal factors work together to produce an individuals' current perception of the police. Life history theory shows that being of a certain ethnicity, age, gender or SES status does not cause someone to hold a certain perception towards the police. Rather, life history theory demonstrates how an individuals' attitude towards the police is based upon an adaptive behavioural response that allows the individual to have the best chance of survival, growth, and successful reproduction in the type of environment in which they reside.

The study provides a useful insight for the police in New Zealand. The police rely on the support of members of the public more than any other public service organization in order to effectively maintain social order and to fight crime (Miller, Davis, Henderson, Markovic \& Ortiz, 2004; Johnson, 1993; Schafer, Huebner \& Bynum 2003; Sunshine \& Tyler, 2003a). It is therefore important that the police understand what may influence public perceptions of the police force, and for them to gain a broader understanding of individual differences in attitudes towards the police.

The current study indicates that people may already hold a positive or negative perception of the police, before they have had any actual contact or interaction with the police, because of their life history strategy. The results of the studies showed that life history theory accounted for the majority of the variance in explaining individual perceptions of the police, even after controlling for prior police interaction. In other words, people with a faster life history had more negative perceptions of police legitimacy and procedural justice even if they had never experienced any form of interaction with the police in their lifetime. Thus, people may be predisposed towards having a certain perception of the police due to their individual life history strategy. This can help to explain how attitudes towards the police are formed, and how they are formed without necessarily having any direct experience with the police. Police 
Perceptions of Procedural Justice and Police Legitimacy: A Life History Perspective

could therefore be mindful of different life history strategies, and be aware that people may have predisposed attitudes towards the police, and the manner in which the police act could either confirm or disconfirm these predisposed ideologies. This is especially important in disadvantaged communities, where those with a faster life history are likely to be disproportionately situated (Chow, 2012; Schafer et al., 2003).

The current study indicates that police should aim to act in a manner that will increase feelings of legitimacy and procedural justice, and this in turn should lead to increased levels of compliance, co-operation, and trust. Tyler (2004) argued that the following 3 features of an interaction between the police and the public were likely to increase the likelihood people would have a positive perception of procedural justice:

1) Active involvement in discussions before the police make their discussions, such as individuals being given the chance to explain their views and behaviour before the police decide on what course of action to take.

2) The police have made decisions that are fair, neutral, and impartial.

3) The police have treated the individual with respect and dignity.

Therefore if the police incorporated these 3 actions into their encounters with the public (when appropriate), individuals may begin to hold more positive perceptions of the police. Again, this is particularly important in areas where those of a faster life history strategy are likely to be located, as these individuals may be predisposed to see the police as competition and to act in an impulsive manner.

The current study also has important implications for policy makers. Life history theory is based on the idea that individuals have a limited number of resources and they need to make trade offs in terms of allocating these resources across their lifespan (Kruger et al., 2011; Olderback, Gladden, Wolf \& Figueredo, 2014; Figueredo et al., 2014; Griskevicius et al., 2011). If policy could increase the 
Perceptions of Procedural Justice and Police Legitimacy: A Life History Perspective

stabilization of environments, then there would be less pressure in terms of allocating resources, and consequently those with a faster life history strategy may begin to shift towards the slower end of the continuum. This could lead to less competition for status and resources, and may increase the overall level of adherence to social structure in these sorts of environments.

\section{Future research}

The current study has shown the value of life history theory and how it can be applied to our understanding of individual differences in attitudes towards the police. Future studies should continue to explore the use of life history strategy in explaining attitudes towards the police, and conduct a study with a larger sample size that would include more variation amongst the life history strategies of participants. This would produce a more generalizable representation of the New Zealand population, and a more generalizable confirmation of the current findings.

More research is needed on the relationship between ethnicity, life history strategy, and perceptions of the police. The current study had a very limited number of ethnic minority participants. In order to get an improved understanding of this relationship, future studies should aim to sample a wider range of different ethnicities. Future research also needs to explore the influence of community dangerousness on attitudes towards the police, and the relationship between community dangerousness and life history. Future research could incorporate more rigorous measures of community dangerousness in their studies. There is also scope to incorporate more rigorous measures of self-reported criminal and anti-social behaviours. For example, people who take or possess illegal drugs may be more inclined to be generally weary of the police regardless of other factors. 
Perceptions of Procedural Justice and Police Legitimacy: A Life History Perspective

As Kruger et al., (2015) recognised in their study, some of the variance found in the current study would likely be explained by heritable genotype. Life history develops in response to both environmental and genetic factors (Durrant \& Ward, 2015; Kruger et al., 2011). Further research is needed to help clarify the interaction between socioenvironmental factors, genetics and life history strategy. Further research could address the extent to which socioenvironmental factors, genetics and life history strategy individually influence attitudes towards the police, and the extent to which these factors interrelate together to influence individual attitudes towards the police.

Lastly, future studies could investigate the most effective and realistic ways that policy makers could work on the stabilization of environments and thus the stabilization of faster life history strategies. The current research has demonstrated how an unstable environment leads to a more negative perception of the police and less cooperation with the police. Therefore this area of research would benefit not only the police force, but also society as a whole.

\section{Conclusion}

The current study aimed to investigate the extent to which life history theory explained individual attitudes towards perceptions of police legitimacy and procedural justice in New Zealand. The findings of the current study demonstrated that individual life history had a fundamental influence on determining individual differences in attitudes towards police legitimacy and procedural justice. The current research extended on the study by Kruger et al. (2015), and showed that life history theory accounted for individual attitudes towards police legitimacy and procedural justice after controlling for demographic factors. Demographic factors had no predictive 
Perceptions of Procedural Justice and Police Legitimacy: A Life History Perspective

value once life history and community dangerousness were entered in the regression models. More specifically, the study found that those with a slower life history strategy were more likely to have a greater perception of police legitimacy and procedural justice compared to those with a faster life history strategy. The current study also found that life history theory accounted for individual attitudes towards police legitimacy and procedural justice after controlling for previous interaction with the police and prior arrest. Thus there was a relationship between life history theory and demographic factors but the demographic factors did not explain individual attitudes towards the police, nor did previous police interaction or prior arrest. In both study 1 and study 2, individual attitudes towards the police were largely explained solely by individual life history strategy. The study also found that a slower life history strategy increased people's willingness to voluntarily contact the police, which is an important finding because prior research has shown that the police find it challenging to gain voluntary co-operation from citizens (Gau, 2014).

The application of a life history strategy provides a new explanation for understanding individual differences in attitudes towards the police. Prior studies have produced inconclusive results concerning the relationship between demographic factors and attitudes towards the police, and the relationship between demographic factors and perceptions of the police is still not clear. The current study has aimed to demonstrate that life history theory can provide a broader understanding behind people's individual attitudes towards the police, and explain why individual attitudes develop in the first place. Life history theory demonstrates how people react to their environment, and how their behaviours and attitudes may be an adaptive response to the conditions in which they reside. 
Perceptions of Procedural Justice and Police Legitimacy: A Life History Perspective

The current research has demonstrated the value that life history theory has in criminological theory and in explaining the behaviours of individuals. The current research also has important implications for the police, policy makers, and for all members of society. Research has shown that a positive perception of police legitimacy and procedural justice leads to more cooperation with the police and more compliance with the laws that they enforce (Sunshine and Tyler, 2003a; Tyler, 2004, Tyler, Fagan \& Geller, 2014). This is beneficial because it helps to maintain order and safety in the community, something that would not be achievable without cooperation and compliance from citizens. Although there were a few limitations to the current research, and a larger sample size is needed in future studies to make the results more generalizable, the current research has provided a solid starting point for the application of life history theory to understanding individual differences in attitudes towards the police. 
Perceptions of Procedural Justice and Police Legitimacy: A Life History Perspective

\section{Appendices}


Perceptions of Procedural Justice and Police Legitimacy: A Life History Perspective

\title{
Appendix A
}

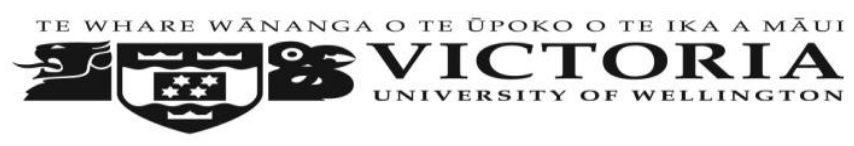

\begin{abstract}
Attitudes Towards The Police Survey
Thank you for agreeing to participate in this research on attitudes towards the police consent to take part in this research will be implied through your voluntary participation in the study. This research is completely anonymous and confidential; you will not be able to be identified in any way. This research is being completed as a part of my masters degree, and has been approved by the Victoria University of Wellington Human Ethics Committee (approval date: 12/08/15, approval number:
\end{abstract} 22065).

Please note, you must be 18 years or older to take part in this research.

It is estimated that the survey will take no more than 10-15 minutes to complete. You are free to exit the questionnaire at any time if you wish to do so, and your responses will not be included. The results from this study will be written up as a part of my master's thesis, and may be published in one or more academic journal.

If you find any of the material in this questionnaire to be distressing you can contact Victim Support on 0800842846 or Crime Stoppers anonymously on 0800555111.

If you have any further questions regarding this research please contact myself, Jody, at Jody.Dorgan@vuw.ac.nz or my supervisor at Victoria University of Wellington, Dr Russil Durrant, at Russil.Durrant@ vuw.ac.nz.

If you have any ethical questions about this research you may contact the Human Ethics Committee Convenor, Associate Professor Susan Corbett, at susan.corbett@vuw.ac.nz or on 044635480. 
Perceptions of Procedural Justice and Police Legitimacy: A Life History Perspective

\section{Please answer the following questions}

What is your gender?

Male

Female

What is your age?

What is your ethnicity? (Please select the group that you identify most strongly with). (NB: The responses listed below were only provided in study 2. In study 1 participants were provided a blank space to write their ethnicity in).

New Zealander/European.

Māori

Asian

Pacific

Indian

Other (please write your ethnicity below if you have selected 'other').

Please indicate the highest level of education you have completed. (NB: This question was only included in study 2).

High school or equivalent

Certificate or equivalent

Diploma

Graduate diploma or certificate

Bachelors degree

Post graduate diploma or certificate

Bachelors degree with honours

Masters degree 
Perceptions of Procedural Justice and Police Legitimacy: A Life History Perspective

Doctorate/PHD

Other (please write your highest level of education below if you have selected 'other').

Please read the following statements and answer each one on a scale from 1 (not dangerous at all) to 5 (very dangerous).

1: Not dangerous at all

2: Somewhat dangerous

3: Dangerous

4: Moderately dangerous

5: Very dangerous

Please think about the community where you spent most of the first 16 years of your life and rate how dangerous you consider it in terms of:

The general crime rate.

The likelihood that you would be attacked or otherwise face physical violence.

The likelihood of your property being stolen or destroyed.

The likelihood of someone being sexually assaulted.

Please read the following statements and answer each one on a scale from 1 (strongly disagree) to 5 (strongly agree).

1: Strongly disagree

2: Disagree

3: Neither agree nor disagree

4: Agree

5: Strongly agree

Please think about the community where you spent most of the first 16 years of your life and the police in that community. Police in my community:

Make decisions that are right for my community.

Intentionally dominate other people.

Maintain order in the community.

Sometimes behave like criminals themselves.

Like to show off.

Treat people fairly. 
Perceptions of Procedural Justice and Police Legitimacy: A Life History Perspective

Explain their decisions to the people they deal with.

Use their power to get things from people.

Get social status from their jobs.

Treat people in the community like an enemy.

Help prevent society from collapsing.

Protect people's basic human rights.

Treat people with dignity and respect.

Are just like any other gang, just more powerful.

Enjoy their power.

Take time to listen to people.

I would contact the police:

To report a crime in my neighbourhood.

To report suspicious activity in my neighbourhood.

If I had information about a suspected criminal.

To find out about crime in the area.

Please read the following statements and answer each one on a scale from 1 (very unlikely) to 5 (very likely).

1: Very unlikely

2: Unlikely

3: Neither unlikely or likely

4: Likely

5: Very likely

If you see a police officer walking towards you on the street, how likely would you be to:

Say hello.

Say hello back if the officer says hello to you.

Start an informal conversation.

Please read the following questions and answer either yes or no. 
Perceptions of Procedural Justice and Police Legitimacy: A Life History

Perspective

1: Yes

2: No

Did the police ever initiate an interaction with you in the community where you spent the first 16 years of your life?

Did you ever initiate an interaction with the police in this community where you spent the first 16 years of your life?

Have you ever been arrested?

Please read the following statements and answer each one on a scale from strongly disagree (1) to strongly agree (7). If the question is not applicable to you, please select 4 (neither agree nor disagree).

1: Strongly disagree

2: Disagree

3: Somewhat disagree

4: Neither agree nor disagree

5: Somewhat agree

6: Agree

7: Strongly agree

I can often tell how things will turn out.

I try to understand how I got into a situation to figure out how to handle it.

I often find the bright side to a bad situation.

I don't give up until I solve my problems.

I often make plans in advance.

I avoid taking risks.

While growing up, I had a close and warm relationship with my biological mother.

While growing up, I had a close and warm relationship with my biological father.

I have a close and warm relationship with my own children.

I have a close and warm romantic relationship with my sexual partner.

I would rather have one than several sexual relationships at a time.

I have to be closely attached to someone before I am comfortable having sex with them.

I am often in social contact with my blood relatives. 
Perceptions of Procedural Justice and Police Legitimacy: A Life History Perspective

I often get emotional support and practical help from my blood relatives.

I often give emotional support and practical help to my blood relatives.

I am often in social contact with my friends.

I often get emotional support and practical help from my friends.

I often give emotional support and practical help to my friends.

I am closely connected to and involved in my community.

I am closely connected to and involved in my religion.

Thank you again for taking the time to participate in this study. If you would like a summary of the results of this research once available, please email Jody.Dorgan@vuw.ac.nz. 


\section{Appendix B}

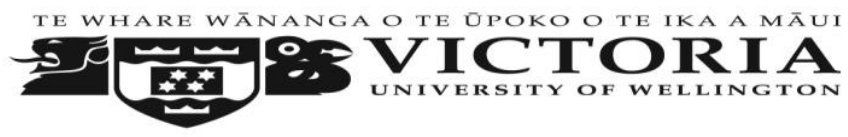

\section{Participant Information Sheet For a Study on Attitudes Towards the Police.}

Researcher: Jody Dorgan, School of Social and Cultural Studies, Victoria University of Wellington.

\section{Seeking your consent to be involved in research}

This information sheet provides details about research that I am conducting about attitudes towards the police. Victoria University makes sure that researchers inform potential participants about their research, and what will be involved for the participant taking part in the study. This research has been approved by the Victoria University of Wellington Human Ethics Committee (approval number: 22065, approval date: 12/08/15).

\section{What is this research about?}

I am a Masters student within the Criminology department at Victoria University of Wellington, and my thesis is looking at perceptions of the police. This research is completely anonymous and confidential; you will not be able to be identified in any way. The results from this study will be written up as a part of my master's thesis and may be published in one or more academic journal.

\section{What does participating in this study involve?}

First you will be asked to identify your gender, age and ethnicity as a part of some general demographic questions. You will not be asked to identify any other information about yourself. You will then be asked some questions about crime in your neighbourhood, followed by some general questions about the police and your experiences with them. Lastly you will be asked some general questions about your personality. You will be asked to answer each question on a scale of either 1-5 or 1-7 
Perceptions of Procedural Justice and Police Legitimacy: A Life History Perspective

(strongly disagree to strongly agree), or with a 'yes' or 'no'. It is estimated that the study will take no more than 10-15 minutes to complete. You are free to exit the questionnaire at any time if you wish to do so, and your responses will not be included.

Consent to take part in this research will be implied through your voluntary participation in the study.

If you find any of the material in this questionnaire to be distressing you can contact Victim Support on 0800842846 or Crime Stoppers anonymously on 0800555111.

If you would like a summary of the results of this research once available, please email Jody.Dorgan@vuw.ac.nz.

\section{Contact Details}

If you have any further questions regarding this research please contact myself, Jody, at Jody.Dorgan@vuw.ac.nz or my supervisor at Victoria University of Wellington, Russil Durrant, at Russil.Durrant@ vuw.ac.nz.

If you have any ethical questions about this research you may contact the Human

Ethics Committee Convenor, Associate Professor Susan Corbett, at susan.corbett@vuw.ac.nz or on 044635480. 


\section{Appendix C}

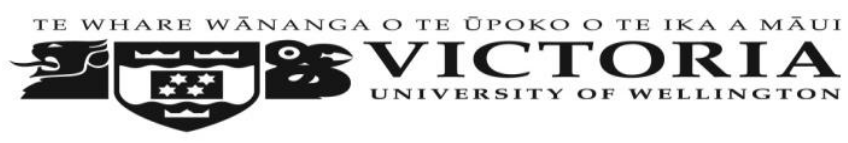

To Whom It May Concern:

Re: Application for digital extract of the electoral roll

I am a Masters student within the Criminology department at Victoria University of Wellington and my thesis aims to assess the extent to which life history strategy can explain perceptions of the police. Previous research has shown a relationship between attitudes towards the police and individual factors such as ethnicity, age, socioeconomic status and neighbourhood characteristics, but the reasons behind these findings have been described as 'fuzzy'. Individual life history strategies can be placed upon a continuum between slow and fast life histories, and differing traits of each strategy can be used to explain differing perceptions of the police. The current study will sample a diverse range of life history strategies and use an online survey to test the hypothesis that a slower life history will predict more favourable attitudes towards the police and greater willingness to collaborate with police in comparison to a fast life history.

In order to ensure that a diverse range of individual life histories are collected, the study needs to sample from a general population across a range of socio-economic areas and ethnicities. I plan to sample my population from the Wellington region and use the electoral roll extract to send out letters based on school deciles to households around the region across various socio-economic areas. This process will be done using random stratified sampling. Each letter will provide a link to on anonymous online survey and will invite participants to take part in the research. The results from the survey will be analysed using regression models to asses the extent to which life history strategy predicts perceptions of the police after controlling for other variables. This research will be completely anonymous and confidential; participants will not be 
Perceptions of Procedural Justice and Police Legitimacy: A Life History Perspective

able to be identified in any way. The electoral roll will be kept on a passwordprotected computer. The Victoria University of Wellington Human Ethics Committee has approved this study. The results from this study will be written up as a part of my master's thesis, and may be published in one or more journal article. 
Perceptions of Procedural Justice and Police Legitimacy: A Life History Perspective

Kind regards,

Jody Dorgan

Jody.Dorgan@vuw.ac.nz

ton

Supervisor:

Dr Russil Durrant

Russil.Durrant@yyuy.ac.nz

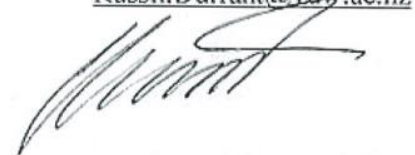

Vice Chancellor Victoria University of Wellington:

Professor Grant Guilford

vice-chancellor@vuw.ac.nz.

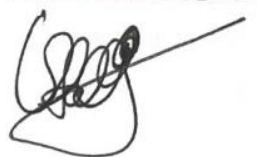




\section{Appendix D}

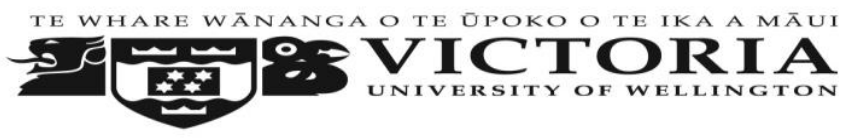

Monday, 29 February 2016

\section{Dear (participant name),}

I am a master's student at Victoria University of Wellington, and am currently undertaking research about public attitudes towards the police. You have been randomly selected from the electoral roll and are invited to take part in a quick online, fully confidential survey that will allow you to express your attitudes towards the police in New Zealand. This research is completely anonymous and confidential; you will not be able to be identified in any way. This research has been approved by the Victoria University of Wellington Human Ethics Committee (approval number: 22065, approval date: 12/08/15).

It is estimated that the study will take no more than 10-15 minutes to complete. You are free to exit the questionnaire at any time if you wish to do so, and your responses will not be included. If you choose to take part in the survey, you will be asked some non-identifying demographic questions, followed by a series of questions that you will rate on a scale of 1-5, 1-7, or 'yes' and 'no'.

If you would prefer to fill out the questionnaire manually and post it back, you can email Russil.Durrant@vuw.ac.nz and this can be arranged. You will be provided with a pre-paid return envelope so you can post it back at no charge to yourself, and again you will remain anonymous and your responses confidential in this scenario too. I will not be able to see who has requested a hard copy of the survey.

Consent to take part in this research will be implied through your voluntary participation in the study. The results from this study will be written up as a part of my master's thesis, and may be published in one or more academic journal.

\section{You can access the survey at:}


Perceptions of Procedural Justice and Police Legitimacy: A Life History Perspective

\section{http://vuw.qualtrics.com/SE/?SID=SV_dciIgwez7qofsAR}

If you have any further questions regarding this research please contact myself, Jody, at Jody.Dorgan@vuw.ac.nz or my supervisor at Victoria University of Wellington, Russil Durrant, at Russil.Durrant@ vuw.ac.nz.

If you have any ethical questions about this research you may contact the Human

Ethics Committee Convenor, Associate Professor Susan Corbett, at susan.corbett@vuw.ac.nz or on 044635480.

Thank you for your consideration to take part in this research,

Jody Dorgan

Victoria Universty of Wellington. 
Perceptions of Procedural Justice and Police Legitimacy: A Life History Perspective

\section{Appendix E}

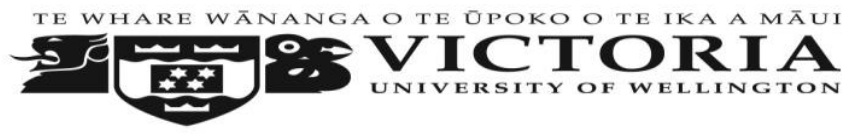

\section{Participant Information Sheet For a Study on Attitudes Towards the Police.}

Researcher: Jody Dorgan, School of Social and Cultural Studies, Victoria University of Wellington.

\section{Seeking your consent to be involved in research}

This information sheet provides details about research that I am conducting about attitudes towards the police. Victoria University makes sure that researchers inform potential participants about their research, and what will be involved for the participant taking part in the study. This research has been approved by the Victoria University of Wellington Human Ethics Committee (approval number: 22065, approval date: 12/08/15).

\section{What is this research about?}

I am a Masters student within the Criminology department at Victoria University of Wellington, and my thesis is looking at perceptions of the police. This research is completely anonymous and confidential; you will not be able to be identified in any way. The results from this study will be written up as a part of my master's thesis, and may be published in one or more academic journal.

\section{What does participating in this study involve?}

First you will be asked to identify your gender, age and ethnicity as a part of some general demographic questions. You will not be asked to identify any other information about yourself. You will then be asked some questions about crime in your neighbourhood, followed by some general questions about the police and your experiences with them. Lastly you will be asked some general questions about your personality. You will be asked to answer each question on a scale of either 1-5 or 1-7 
Perceptions of Procedural Justice and Police Legitimacy: A Life History Perspective

(strongly disagree to strongly agree), or with a 'yes' or 'no'. It is estimated that the study will take no more than 10-15 minutes to complete. You are free to exit the questionnaire at any time if you wish to do so, and your responses will not be included.

If you would prefer to fill out the questionnaire manually and post it back, you can email Russil.Durrant@vuw.ac.nz and this can be arranged. You will be provided with a pre-paid return envelope so you can post it back at no charge to yourself, and again you will remain anonymous and your responses confidential in this scenario too. The data will be entered by the researcher, with no identifying information about participants. This will ensure that there will be no way to link the responses to individuals who requested the hard copy of the survey.

Consent to take part in this research will be implied through your voluntary participation in the study.

If you find any of the material in this questionnaire to be distressing you can contact Victim Support on 0800842846 or Crime Stoppers anonymously on 0800555111.

If you would like a summary of the results of this research once available, please email Jody.Dorgan@vuw.ac.nz.

\section{Contact Details}

If you have any further questions regarding this research please contact myself, Jody, at Jody.Dorgan@vuw.ac.nz or my supervisor at Victoria University of Wellington, Russil Durrant, at Russil.Durrant@vuw.ac.nz.

If you have any ethical questions about this research you may contact the Human Ethics Committee Convenor, Associate Professor Susan Corbett, at susan.corbett@vuw.ac.nz or on 044635480. 
Perceptions of Procedural Justice and Police Legitimacy: A Life History Perspective

\section{References}

Archer, J. (2009). Does sexual selection explain human sex differences in aggression? Behavioural and Brain Sciences, 32, 249-311.

Bogaert, A.F \& Rushton, J.P. (1989). Sexuality, delinquency and r/K reproductive strategies: Data from a Canadian university sample. Personality and Individual Differences, 10 (10), 1071-1077.

Boutwell, B.B., Barnes, J.C., Beaver, K.M., Haynes, R.D., Nedelec, J.L., \& Gibson, C.L. (2015). A unified crime theory: The evolution of taxonomy. Aggression and Violent Behaviour, 25, 343-353.

Bradley, T., \& Walters, R. (2011). Introduction to Criminological Thought (2 ${ }^{\text {nd }}$ Ed.). Auckland: Pearson.

Brandt, D.E., \& Markus, K.A. (2000). Adolescent attitudes towards the police: A new generation. Journal of Police and Criminal Psychology, 15, 10-16.

Brown, B., \& Benedict, W.R. (2002). Perceptions of the police: Past findings, methodological issues, conceptual issues and policy implications. Policing: An International Journal of Police Strategies \& Management, 25 (3), 543- 580.

Campbell, A. (2013). A Mind of Her Own: The Evolutionary Psychology of Women $\left(2^{\text {nd }}\right.$ ed.). New York: Oxford University Press.

Cauffman, E., Cavanagh, C., Donley, S., \& Thomas, A.G. (2015). A developmental perspective on adolescent risk-taking and criminal behaviour. In A. Piquero (Eds.), The handbook of criminological theory (pp. 100-113). Oxford: WileyBlackwell.

Chow, H. P. H. (2012). Attitudes towards police in Canada: A study of perceptions of university students in a Western Canadian city. International Journal of Criminal Justice Sciences, 7 (1), 508-523.

Correia, M. E., Reisig, M. D., \& Lovrich, N. P. (1996). Public perceptions of state police: An analysis of individual-level and contextual variables. Journal of Criminal Justice, 24 (1), 17-28.

Creswell, J.W. Research Design: Qualitative, Quantitative, and Mixed Methods Approaches ( $2^{\text {nd }}$ Ed.). California: Sage Publications. 
Perceptions of Procedural Justice and Police Legitimacy: A Life History Perspective

Daly, M., \& Wilson, M. (1990). Killing the competition: Female/female and male/male homicide. Human Nature, 1:1, 81-107.

Del Giudice, M., Gangestad, S.W., \& Kaplan, H.S. (2015). Life history theory and evolutionary psychology. In D.M Byss (Ed.), The handbook of evolutionary psychology - Vol 1: Foundations (2 ${ }^{\text {nd }}$ ed.) (pp. 88-114). New York: Wiley.

Devaney, L., Pehrson, S., Bryan, D., \& Blaylock, D. (2014). The Dynamics of Police Legitimacy among Young People. Belfast: Queen's University.

Dunkel, C., Mathes, E., \& Beaver, K. (2013). Life history theory and the general theory of crime: Life expectancy effects on low-self control and criminal intent. Journal of Social, Evolutionary, and Cultural Psychology, 7 (1), 12-23.

Durrant, R., \& Ellis, B.J. (2013). Evolutionary psychology. In R.J. Nelson \& S.J.Y. Mizumori (Eds.), Handbook of psychology, Vol. 3: Behavioral neuroscience (2nd Ed.) (pp. 26-51). Hoboken, New Jersey: John Wiley \& Sons.

Durrant, R., \& Ward, T. (2011). Evolutionary explanations in the social and behavioural sciences: introduction and overview. Aggression and Violent Behaviour, 16, 361-370.

Durrant, R., \& Ward, T. (2015). Evolutionary Criminology: Towards a Comprehensive Explanation for Crime. San Diego, CA: Elsevier.

Ellis, B. J., Dishion, T. J., Gray, P., Hawley, P. H., Volk, A. A., Del Giudice, M., et al., (2012). The evolutionary basis of risky adolescent behaviour: implications for science, policy and practice. Developmental Psychology, 48, 598-623.

Ellis, B.J., Figueredo, A.J., Brumbach, B.H \& Schlomer, G.L. (2009). Fundamental dimensions of environmental risk: the impact of harsh versus unpredictable environments of the evolution and development of life history strategies. Human Nature, 20, 204-268.

Fagan, J., \& Tyler, T. R. (2005). Legal socialization of children and adolescents. Social justice research, 18(3), 217-241.

Figueredo, A.J., Vasquez, G., Brumbach, B.H., Sefcek, J.A., Kirsner, B.R., \& Jacobs, W.J. (2005). The K-factor: Individual differences in life history strategy. Personality and Individual Differences, 39, 1349-1360.

Figueredo, A.J., Olderback, S.G., Wolf, P.S.A., Gladden, P.R., Fernandes, H.B.F., Wenner, C........Rushton, J.P. (2014). The psychometric assessment of 
Perceptions of Procedural Justice and Police Legitimacy: A Life History Perspective

human life history strategy: A meta-analytic construct validation. Evolutionary Behavioural Sciences, 8 (3), 148-185.

Gau, J.M. (2014). Procedural justice and police legitimacy: A test of measurement and structure. American Journal of Criminal Justice, 39, 187-205.

Greene, J.R. (2000). Community policing in America: Changing the nature, structure, and function of the police. Criminal Justice, 3 (3), 299-378.

Griskevicius, V., Tybur, J. M., Delton, A. W., \& Robertson, T. E. (2011). The influence of mortality and socioeconomic status on risk and delayed rewards: a life history theory approach. Journal of personality and social psychology, 100(6), 1015.

Hinds, L. (2007). Building police-youth relationships: The importance of procedural justice. Youth Justice, 7(3), 195-209.

Hinds, L., \& Murphy, K. (2007). Public satisfaction with the police: Using procedural justice to improve police legitimacy. The Australian and New Zealand Journal of Criminology, 40 (1), 27-42.

Hoffman, M. L. (1977). Moral internalization: Current theory and research. Advances In Experimental Social Psychology, 10, 85-133.

Ho, E.S., Cooper, J., \& Rauschmayr, B. (2006). Ethnic community perceptions of the police (1-69), The New Zealand Police.

Hurst, Y. G., \& Frank, J. (2000). How kids view cops: The nature of juvenile attitudes toward the police. Journal of Criminal Justice, 28, 189-202.

Johnson, T. R. (1993). The public and the police in the city of Chicago. Center for Urban Affairs and Policy Research, Northwestern University.

Jones, J. H. (2009). The force of selection on the human life cycle. Evolution and Human Behaviour, 30 (5), 305-314.

Kruger, D.J., \& Nedelec, J. (2014). Life history predicts perceptions of procedural justice and police legitimacy. Presentation, Human Behaviour and Evolution Society. 
Perceptions of Procedural Justice and Police Legitimacy: A Life History Perspective

Kruger, D.J., Nedelec, J., Reischl, T.M., \& Zimmerman, M.A. (2015). Life history predicts perceptions of procedural justice and crime reporting intentions. Evolutionary Psychological Science, 1, 183-194.

Kruger, D.J., \& Nesse, R.M. (2006). An evolutionary life-history framework for understanding sex differences in human mortality rates. Human Nature, 17 (1), 74-97.

Kruger, D.J., Munsell, M.A., French Turner, T. (2011). Using a life history framework to understand the relationship between neighbourhood structural deterioration and adverse birth outcomes. Journal of Social, Evolutionary, and Cultural Psychology, 5 (4), 260-274.

Laub, J. H. (2006). Edwin H. Sutherland and the Michael-Adler report: Searching for the soul of criminology seventy years later. Criminology, 44, 235-257.

MacCoun, R. J. (1993). Drugs and the law: A psychological analysis of drug prohibition. Psychological Bulletin, 113, 497-512.

Maxwell, G., \& Smith, C. (1998). Police perceptions of Maori. (1-82). Wellington: Victoria Link Ltd.

Mazerolle, L., Antrobus, E., Bennett, S., \& Tyler, T. (2012). Shaping citizens perceptions of police legitimacy: A randomized field trial of procedural justice. American Society of Criminology, 51 (1), 33-64.

Miller, J., Davis, R.C., Henderson, N.J., Markovic, J., \& Ortiz, C.W. (2004). Public opinions of the police: The influence of friends, family, and news media. US Department of Justice, 1-165.

Ministry of Education. (2016). School deciles. Retrieved from www.education.govt.nz.

Murphy, K., \& Cherney, A. (2011). Understanding cooperation with police in a diverse society. British Journal of Criminology, 52, 181-201.

Nettle, D. (2010). Dying young and living fast: Variation in life history across English neighbourhoods. Behavioural Ecology, 10, 387-395.

Newman, I., \& Benz, C.R. (1998). Qualitative-Quantitative Research Methodology: Exploring the Interactive Continuum. Illinois: Southern Illinois University Press.

New Zealand Post. (2016). Postcode directory. Retrieved from www.nzpost.co.nz. 
Perceptions of Procedural Justice and Police Legitimacy: A Life History Perspective

O'Connor, C, D. (2008). Citizen attitudes toward the police in Canada. Policing: An International Journal of Police Strategies \& Management, 31 (4), 578-595.

Olderbak, S., Gladden, P., Wolf, P.S.A., \& Figueredo, A.J. (2014). Comparison of life history strategy measures. Personality and Individual Differences, 58, 82-88.

Paulin, J., Searle, W., \& Knaggs, T. (2003). Attitudes to crime and punishment: A New Zealand study. (1-144). Wellington: Ministry of Justice.

Posick, C., Rocque, M., \& McDevitt, J. (2013). One scale fits all? Assessing racial differences in the measurement of attitudes toward the police. Race and Justice, 3, 190-209.

Quince, K. (2007). Maori and the criminal justice system in New Zealand. In Tolmie, J., \& Brookbanks, W (E.d), Criminal Justice in New Zealand (1-26). Auckland: LexisNexis New Zealand Ltd.

Reisig, M. D., \& Parks, R. B. (2000). Experience, quality of life, and neighborhood context: A hierarchical analysis of satisfaction with police. Justice quarterly, 17(3), 607-630.

Richardson, G.B., Dai, C., Chen, C., Nedelec, J.L, Swoboda, C.M., \& Chen, W. (2016). Adolescent life history strategy in the intergenerational transmission and developmental stability of substance use. Journal of Drug Issues, 46 (1), $1-20$.

Rushton, J.P. (1985). Differential K theory: The sociobiology of individual and group differences. Person. individ. diff, 6 (4), 441-452.

Sargeant, E., \& Mazerolle, L. (2012). Gender and perceptions of police: Findings from the Australian community capacity study. Australian Policing: A Journal of Professional Practice and Research, 17-19.

Scaglion, R., \& Condon, R. (1980). Determinants of attitudes toward city police. Criminology, 17 (4), 485-494.

Schafer, J.A., Huebner, B.M., \& Bynum, T.S. (2003). Citizen perceptions of police services: Race, neighbourhood context, and community policing. Police Quarterly, 6 (4), 440-468.

Schuck, A.M., Rosenbaum, D.P., \& Hawkins, D.F. (2008). The influence of race/ethnicity, social class, and neighbourhood context on residents attitudes towards the police. Police Quarterly, 11 (4), 469-519. 
Perceptions of Procedural Justice and Police Legitimacy: A Life History Perspective

Skogan, W.G. (2005). Citizen satisfaction with police encounters. Police Quarterly, 8 (3), 298-321.

Smith, A. R., Chein, J., \& Steinberg, L. (2013). Impact of socio-emotional context, brain development, and pubertal maturation on adolescent risk-taking. Hormones and Behaviour, 64(2), 323-332.

Statistics New Zealand. (2015). 2013 census: Major ethnic groups in New Zealand. Retrieved from http://www.stats.govt.nz/Census/2013-census/profile-andsummary-reports/infographic-culture-identity.aspx.

Steinberg, L. (2007). Risk taking in adolescence: New perspectives from brain and behavioural science. Current Directions in Psychological Science, 16 (2), 5559.

Stewart, D.N., Morris, R.G., \& Weir, H. (2014). Youth perceptions of the police: Identifying trajectories. Youth Violence and Juvenile Justice, 12 (1), 22-39.

Sun, I. Y., \& Triplett, R. A. (2008). Differential perceptions of neighborhood problems by police and residents: The impact of neighborhood-level characteristics. Policing: An International Journal of Police Strategies \& Management, 31(3), 435-455.

Sunshine, J., \& Tyler, T. (2003a). The role of procedural justice and legitimacy in shaping public support for policing. Law \& Society Review, 37 (3), 513-537.

Sunshine, J., \& Tyler, T. (2003b). Moral solidarity, identification with the community, and the importance of procedural justice: The police as prototypical representatives of a group's moral values. Social Psychology Quarterly, 66 (2), 153-165.

Te Whaiti, P., \& Roguski, M. (1998). Maori perceptions of the police. (1-82). Wellington: Victoria Link Ltd.

Thibaut, J., \& Walker, L. (1975). Procedural justice: A psychological analysis, Hillsdale: Erlbaum.

Tyler, T.R. (1990). Why people obey the law. New Haven, CT: Yale University Press.

Tyler, T.R., \& Huo, Y.J. (2002). Trust in the law: Encouraging public cooperation with the police and courts. New York: Russell Sage. 
Perceptions of Procedural Justice and Police Legitimacy: A Life History Perspective

Tyler, T. (2004). Enhancing police legitimacy. The Annals of the American Academy, 593, 84-99.

Tyler, T. (2006). Psychological perspectives on legitimacy and legitimation. Annual Review Psychology, 57, 375-400.

Tyler, T., \& Fagan, J. (2008a). Legitimacy and cooperation: Why do people help the police fight crime in their communities? Ohio State Journal of Criminal Law, 6, 231-275.

Tyler, T., \& Fagan, J. (2008b). Why do people cooperate with the police? Ohio State Journal of Criminal Law, 6, 231-275.

Tyler, T. R., Fagan, J., \& Geller, A. (2014). Street Stops and Police Legitimacy: Teachable Moments in Young Urban Men's Legal Socialization. Journal of Empirical Legal Studies, 11(4), 751-785.

Viki, T., Eller, A., \& Abrams, D. (2006). Race and willingness to cooperate with the police: The roles of quality of contact, attitudes toward the behaviour and subjective norms. British Journal of Social Psychology, 45, 285-302.

Wiebe, R. P. (2012). Integrating criminology through adaptive strategy and life history theory. Journal of Contemporary Criminal Justice, 28 (3), 346-365.

Wilson, M., \& Daly, M. (1997). Life expectancy, economic inequality, homicide, and reproductive timing in Chicago neighborhoods. British Medical Journal, 314, 1271-1274.

Weitzer, R. (1999). Citizens' perceptions of police misconduct: Race and neighbourhood context. Justice Quarterly, 16 (4), 819-846.

Weitzer, R., \& Tuch, S.A. (2004). Reforming the police: Racial differences in public support for change. Criminology, 42 (2), 391-416. 
Perceptions of Procedural Justice and Police Legitimacy: A Life History Perspective 